\title{
Genetic Structure and Origin of Peopling in The Azores Islands (Portugal): The View from mtDNA
}

\author{
C. Santos ${ }^{1,2, *}$, M. Lima ${ }^{3}$, R. Montiel ${ }^{3,1}$, N. Angles', L. Pires², A. Abade ${ }^{2}$ and Ma. P. Aluja' \\ ${ }^{1}$ Unity of Anthropology, Department BABVE, Faculty of Sciences, Autonomous University of Barcelona, \\ 08193 Bellaterra (Barcelona), Spain \\ ${ }^{2}$ Department of Anthropology, University of Coimbra, 3000 Coimbra, Portugal \\ ${ }^{3}$ CIRN and Department of Biology, University of the Azores, 9500 Ponta Delgada, S. Miguel, Azores, Portugal
}

\section{Summary}

The Azores islands (Portugal), uninhabited when discovered by Portuguese navigators in the fifteenth century, are located in the Atlantic Ocean $1500 \mathrm{~km}$ from the European mainland. The archipelago is formed by nine islands of volcanic origin that define three geographical groups: Eastern (S. Miguel and Sta. Maria), Central (Terceira, Faial, Pico, Graciosa and S. Jorge) and Western (Flores and Corvo). To improve the genetic characterisation of the Azorean population, and to clarify some aspects related to the history of settlement, a study of mtDNA was conducted in the population of the archipelago. The HVRI region was sequenced and specific RFLPs were screened in 146 samples obtained from unrelated individuals with Azorean ancestry (50 from the Eastern group, 60 from the Central group, and 37 from the Western group). Samples were classified into haplogroups based on the information obtained from both sequencing and RFLP analysis.

All the analyses performed support the idea that, in the whole group of islands, the majority of mtDNA lineages originated from the Iberian Peninsula, mainly from Portugal (mainland). However contributions from other European populations, especially from Northern Europe, cannot be disregarded. The values obtained for the various diversity parameters in the Azores archipelago indicate that the Azorean population, as a whole, does not exhibit the typical characteristics of an isolated population. The analysis of genetic data by groups of islands showed that the Western group exhibited particular features. The distribution of haplogroups in the Western group is very atypical, being significantly different from what is observed in the Eastern and Central groups. Furthermore, the diversity values are, in general, lower than those observed in other populations used for comparison. African haplogroups were found in all the groups of islands. Therefore the presence of Moorish and African slaves on the islands, as reported in historical sources, is supported by the mtDNA genetic data, especially in the Eastern group. The presence of Jews in the Central group is also supported by the mtDNA data. Neither historical nor genetic data (phylogeography of mtDNA) supports the idea of a differential settlement history for the Western group; however, it is represented in the phylogenies as an isolated branch. The effect of genetic drift, induced by the reduced population size since peopling occurred, has led to a very atypical distribution of haplogroups/haplotypes in this group of islands.

We cannot ignore the influence of biodemographic and genetic processes, namely founder effect, genetic drift, migration, and even recent mutational events in the mtDNA lineages of the Azorean populations. Nevertheless, a great part of the variation in the Azorean mtDNA can be explained by the settlement history.

* Corresponding author: Cristina Santos, Unity of Anthropology, Department BABVE, Faculty of Sciences, Autonomous University of Barcelona, 08193 Bellaterra (Barcelona), Spain, Fax: +34 935811321, e-mail: Cristina.Santos@uab.es 


\section{Introduction}

The Azores archipelago (Portugal), located in the Atlantic Ocean, $1500 \mathrm{~km}$ from the European mainland, is formed by nine islands of volcanic origin whose relative positions define three geographical groups: Eastern (S. Miguel and Sta. Maria), Central (Terceira, Faial, Pico, Graciosa and S. Jorge) and Western (Flores and Corvo). With an area of $2344 \mathrm{~km}^{2}$, the Azores presently has a total population of 237315 inhabitants, distributed in a very asymmetric way among the three groups of islands (134885 in the Eastern group, 98101 in the Central group, and only 4329 in the Western group) (INE, 2001).

Historical data indicates that the islands were uninhabited when discovered by Portuguese navigators in the fifteenth century. The peopling of the islands was a slow and difficult process, and was initiated in 1439 in the islands of Sta. Maria and S. Miguel; the small islands of Flores and Corvo were only inhabited towards the end of 16th century (Matos, 1989; Mendonça, 1996). According to historical records, the first settlers came mainly from various regions of mainland Portugal and from Madeira Island. However, people of different origin, such as Spanish, French, Italian, English, German and Flemish (whose important presence is always referred to in accounts of the peopling of the Central group), also made up part of the early settlers (Matos, 1989; Mendonça, 1996). There is clear evidence that Jews also contributed to the peopling of the archipelago. Sephardim Jews expelled from the Iberian Peninsula may have used the Azores as a refuge. The presence of African and Moorish slaves in the islands is also referred to in historical documents (Matos, 1989; Mendonça, 1996), being well-documented especially for the Western group (Gomes, 1997). However, the specific contribution of these settlers to the different islands is not clear, due to the lack of both historical and genetic data.

The complex process of peopling, the evolution of island populations, always affected by migration along with geographic isolation, has been the main stimulus for carrying out biodemographic and genetic studies on the Azorean population. To improve the genetic characterisation of this population and enhance our knowledge about several aspects related to its origin and dynamics, a research project that includes the analysis of nuclear autosomal markers, Y chromosomal and mitochondrial DNA (mtDNA), is presently being undertaken by our group. Here we present the results of the sequencing of HVRI, and specific RFLP screening of mtDNA. Our main goals were: (i) to describe the variation of $\mathrm{mtDNA}$ in the Azorean population; (ii) to gather data in order to contribute to the establishment of the genetic profile of the archipelago; (iii) to shed more light on some aspects related to the history and dynamics of the settlement of the Azores.

\section{Material and Methods}

\section{Samples}

One hundred and forty-six unrelated individuals, born in the Azores and with Azorean ancestry, were sampled, including 42 previously tested by Pires (1999). The birthplace of the earliest known maternal ancestor was chosen as the sample location. Fifty individuals were originally from the Eastern Group, 60 from the Central Group, and 36 from the Western Group. The samples were taken by buccal swabs and existing samples collected by Pires (1999) by venupuncture. Voluntary donors were asked for informed consent and to fill in an anonymous inquiry concerning the birthplaces of all their known ancestors. The comparative data set consisted of 1493 mtDNA HVRI sequences from the populations listed in Table 1. Populations were selected, when possible, in order to include groups that are mentioned in historical documents as sources of settlers for the Azores islands.

\section{DNA Extraction}

Total DNA from buccal cells was extracted using Instagene matrix (BioRad) according to the manufacturer's specifications. DNA from blood samples was previously extracted by Pires (1999) using standard protocols.

\section{MtDNA Analysis}

\section{RFLP Analysis}

Relevant restriction sites for mtDNA haplogroup determination (Table 2) were selected from those 
mtDNA in the Azores Islands (Portugal)

Table 1 Population (corresponding codes in Figure 2), sample size, references and source of the information used in this study

\begin{tabular}{|c|c|c|c|}
\hline Population & $\mathrm{N}$ & Reference & Source \\
\hline Azores - Eastern Group & 50 & This work & This study \\
\hline Azores - Central Group & 60 & $\begin{array}{l}\text { This work, } \\
\text { Pires, } 1999\end{array}$ & $\begin{array}{l}\text { This study, } \\
\text { Provided by the author }\end{array}$ \\
\hline Azores - Western Group & 36 & This work & This study \\
\hline Mainland North Portugal (Pt) & 100 & Pereira et al. 2000 & GenBank \\
\hline Mainland Central Portugal (Pt) & 82 & Pereira et al. 2000 & GenBank \\
\hline Mainland South Portugal (Pt) & 59 & Pereira et al. 2000 & GenBank \\
\hline Spain (Mainland) (Sp) & 89 & $\begin{array}{l}\text { Côrte-Real et al. } 1996 \text {; } \\
\text { Pinto et al. } 1996\end{array}$ & HVRbase (Handt et al. 1998) ${ }^{1}$ \\
\hline Galicia (Sp) & 92 & Salas et al. 1998 & HVRbase (Handt et al. 1998) ${ }^{1}$ \\
\hline Basque Country (Sp) & 106 & $\begin{array}{l}\text { Bertranpetit et al. } 1995 ; \\
\quad \text { Côrte-Real et al. } 1996\end{array}$ & HVRbase (Handt et al. 1998) ${ }^{1}$ \\
\hline France $(\mathrm{Fr})$ & 50 & Rousselet \& Mangin, 1998 & HVRbase (Handt et al. 1998) ${ }^{1}$ \\
\hline UK (UK) & 100 & Piercy et al. 1993 & HVRbase (Handt et al. 1998) ${ }^{1}$ \\
\hline Germany (Ger) & 67 & Hofmann et al. 1997 & HVRbase (Handt et al. 1998) ${ }^{1}$ \\
\hline Austria (Aus) & 101 & Parson et al. 1998 & HVRbase (Handt et al. 1998) ${ }^{1}$ \\
\hline Italy (It) & 49 & Francalacci et al. 1996 & HVRbase (Handt et al. 1998) ${ }^{1}$ \\
\hline Israel Arabs/Palestinians (Isr) & 117 & $\begin{array}{l}\text { Di Rienzo \& Wilson, 1991; } \\
\text { Richards et al. } 2000\end{array}$ & Database of Richards et al. $2000^{2}$ \\
\hline Algeria (Alg) & 85 & Côrte-Real et al. 1996 & HVRbase (Handt et al. 1998) ${ }^{1}$ \\
\hline Moroccan Jews (MJ) & 115 & Thomas et al. 2002 & Provided by the author \\
\hline Morocco (Berber) (MBer) & 60 & Rando et al. 1998 & Provided by the author \\
\hline Morocco (Moroccans) (Mor) & 32 & Rando et al. 1998 & Provided by the author \\
\hline Senegal (Sen) & 119 & $\begin{array}{l}\text { Graven et al. } 1995 \\
\quad \text { Rando et al. } 1998\end{array}$ & $\begin{array}{l}\text { HVRbase (Handt et al. 1998) } \\
\text { Provided by the author }\end{array}$ \\
\hline Mauritania (Maur) & 30 & Rando et al. 1998 & Provided by the author \\
\hline S. Tome (ST) & 50 & Mateu et al. 1997 & Article \\
\hline Mozambique (Moz) & 109 & Pereira et al. 2001 & Article \\
\hline
\end{tabular}

${ }^{1}$ http://www.hvrbase.de

${ }^{2}$ http://www.stats.ox.ac.uk/ macaulay/founders2000/tableA.html

proposed by Torroni et al. (1993, 1994, 1996), Torroni \& Wallace (1994), Chen et al. (1995), Macaulay et al. (1999), Quintana-Murci et al. (1999) and Saillard et al. (2000). Some of the specific primers and PCR conditions for each polymorphic site were available from the literature, but others were designed in our laboratory (Montiel, 2001; Santos, 2001).

Six $\mu 1$ of PCR product were used in restriction enzyme digestions and the enzymatic cleavage was performed according to the manufacturer's specifications. Results of restriction analyses were resolved through electrophoresis in agarose gels (2\%).

\section{HVRI Amplification and Sequencing}

Sequencing was performed for all samples, except those previously sequenced by Pires (1999). A fragment of 443 bp from the HVRI, located between positions
15978 and 16420 (numbered according to Anderson et al. 1981), was amplified using primers and PCR conditions described by Pereira et al. (2000). PCR products were purified using the QIAquick PCR purification kit (Quiagen). Sequence reactions were carried out using the kit ABI PRISM BigDye Terminator version 3 and run in an ABI3100 sequencer (Perkin Elmer).

\section{Data Analysis}

Sequences were aligned and manually checked using BioEdit (Hall, 1999), and all polymorphic positions were confirmed in chromatograms. Sequences without ambiguities were obtained between positions 16050 and 16399. The classification of all the samples by assigning them to haplogroups was performed 


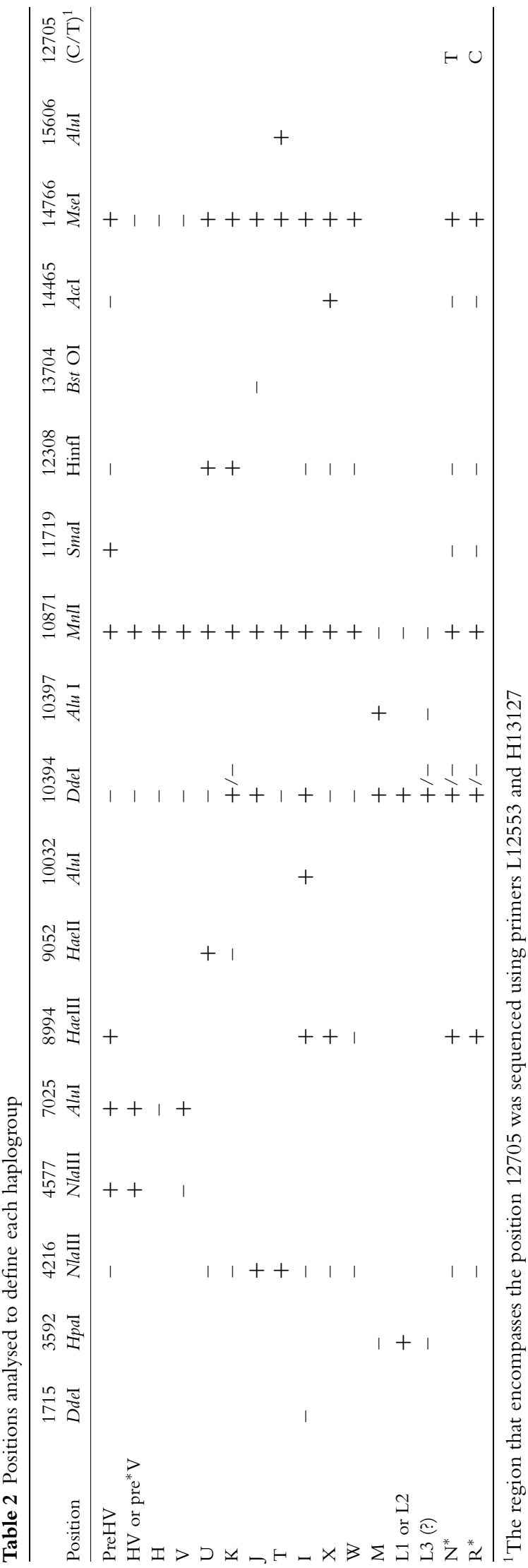

using the combined information of RFLPs and HVRI motifs, according to the nomenclature summarized in Richards et al. (2000), available at: http://www.stats.ox. ac.uk/ macaulay/founder2000/motif.html (Macaulay, 2000). Furthermore, to classify African sequences, a comparison with published data (Pereira et al., 2001) was performed. In order to maximise the number of sequences available for population comparison, all analyses based on sequences were restricted to the $302 \mathrm{nu}-$ cleotides between positions 16069 and 16370 .

The haplogroup distribution in the three groups of islands was used to perform an exact test of population differentiation, as described in Raymond \& Rousset (1995). The exact test was also used to compare frequencies of each haplogroup in the three groups of islands.

For each population, using the HVRI sequence, standard and molecular diversity indices were estimated using the Arlequin 2.000 software (Schneider et al. 2000); namely, gene diversity $(\hat{H})$ (Nei, 1987), number of different haplotypes $(K)$, number of polymorphic sites $(S)$, mean number of pairwise differences $\left(\theta_{\pi}\right)$ (Tajima, 1983), nucleotide diversity $(\pi)$ (Tajima, 1983; Nei, 1987), and the theta estimator based on the number of different haplotypes $\left(\theta_{k}\right)$ (Ewens, 1972). For the major haplogroups found in the Azores (and for comparison in mainland Portugal), $\hat{H}$ (Nei, 1987), $\theta_{\pi}$ (Tajima, 1983), $\pi$ (Tajima, 1983; Nei, 1987) and the average number of sites differing between a set of sequences and a specified common ancestor $(\rho)$ (Forster et al. 1996) were estimated.

Phylogenetic networks (Bandelt et al. 1999) among haplotypes were constructed using the program Network 3.1 (www.fluxus-engineering.com). Positions of HVRI were weighted as proposed by Richards et al. (1998).

Genetic distance matrices, according to Reynolds et al. (1983), were computed in Arlequin 2.000 software (Schneider et al. 2000) and were used as in-files in the Neighbour program from the Phylip ver 3.57c package (Felsenstein, 1995), to construct NeighbourJoining trees (Saitou \& Nei, 1987). Neighbour-Joining trees were drawn with TreeView (Page, 1996).

The analysis of non-parametric correlations between the percentage of private lineages and $\theta_{\mathrm{k}}$ was performed using the statistical package SPSS 9.0.0 (SPSS inc., 1989-1999). 


\section{Results and Discussion}

\section{Sequencing and RFLP Results}

Data obtained for each sample from HVRI sequencing and RFLP analysis, as well as the haplogroup determined from the RFLP and HVRI motifs, are presented in the appendix. It was possible, using the combined information provided for both systems of mtDNA analysis, to classify all samples into one of the haplogroups described in the literature. This work confirms the previously established correlation between RFLPs and HVRI data (Torroni et al. 1996; Francalacci et al. 1999; Macaulay et al. 1999), and supports the idea that a correct and complete classification of mtDNA is only possible when both methods of analysis are used simultaneously.

\section{Haplogroup Frequencies}

The haplogroup frequencies observed in the total sample of the Azores, as well as the partial frequencies observed in the Eastern, Central and Western groups, are summarised in Table 3. The 146 samples were distributed among 31 different haplogroups/sub-haplogroups. Distinct numbers of clusters were found in the Eastern (21), Central (19) and Western (11) groups. The comparison of the haplogroup distribution in the three groups of islands, using the exact test of population differentiation, revealed that there is a similarity between the Eastern and Central groups $(p=0.29955)$. The Western group showed significant differences when compared with the other two groups (Western/Eastern: $\mathrm{p}<0.00001$; Western/Central: $\mathrm{p}=0.00135$ ).

A comparison of the frequencies of each haplogroup in the three groups revealed that haplogroups J, U and V contribute to significantly differentiate the three groups of islands, and largely to differentiate the Western group (significant differences: J-Western/Central/Eastern: $\mathrm{p}=0.04084$, Western/Eastern: $\mathrm{p}=0.038$, Western/ Central: $p=0.023$; U-Western/Central/Eastern: $p=$ 0.00056, Eastern/Central: $p<0.0001$; V-Western/ Central/Eastern: $\mathrm{p}<0.0001$, Western/Eastern: $\mathrm{p}<$ 0.0001, Western/Central: $\mathrm{p}<0.0001)$.

In the total sample of the Azores, all European haplogroups (Torroni et al. 1996) were found, as well as the African clusters U6, M1, L1, L2 and L3 (Rando et al. 1998; Quintana-Murci et al. 1999; Chen et al. 1995, 2000; Watson et al. 1997) and the Near Eastern N1b cluster (Richards et al. 2000). This result provides evidence for a mixed composition of mtDNAs in the Azores islands, that is supported by historical data referring to the contribution of individuals from multiple origins to the peopling of the archipelago.

The analysis by groups (Table 3) revealed that in the Central group, all the main European haplogroups (Torroni et al. 1996) were found. A very low frequency of haplogroup U was observed when compared to values observed in European populations. The frequency of $\mathrm{J}$ is closer to that observed in North European populations. The frequencies of the remaining haplogroups were similar to those observed in European populations. African (M1, L1) and Near Eastern (N1b) sequences were found in low frequencies in the Central group.

In the Eastern Group, and when considering European haplogroups, only I is absent. The most interesting features are the low frequency of haplogroup $\mathrm{H}(30 \%)$, with respect to European populations, and the higher number of sub-clusters of haplogroup $U$ relative to the Western and Central groups of the archipelago. In the Eastern group, high frequencies of non-European sequences were observed, with members of the U6, M1, L2 and L3 African clusters and N1b Near Eastern cluster detected.

The Western group exhibited a very atypical haplogroup distribution, where the I, J and W haplogroups are absent. Haplogroup $\mathrm{U}$ (excluding $\mathrm{K}$ ) is underrepresented, and the few samples belonging to this cluster are members of the U2 and U6b sub-haplogroups, which are uncommon in European populations but more frequent in Near Eastern and North African populations, respectively (Macaulay et al. 1999). The most frequent haplogroup is not $\mathrm{H}$, as it is in European populations, but $\mathrm{V}$, the frequency of which was higher than $33 \%$. In all the results published so far, frequencies of $\mathrm{V}$ higher than $10 \%$ were only found in Catalonia (12.5\%) (Montiel et al. 2001), the Basque Country (12.4\%) and the Skolt Saami (52\%) (Torroni et al. 2001). Members of the East African M1 cluster were also found in this group of islands. 
Table 3 mtDNA haplogroup distribution (number of individuals and percentage) in the total sample of the Azores, and in Eastern, Central and Western groups

\begin{tabular}{|c|c|c|c|c|c|c|c|c|}
\hline \multirow[b]{2}{*}{ Haplogroup } & \multicolumn{2}{|c|}{ Azores $(\mathrm{N}=146)$} & \multicolumn{2}{|c|}{ Eastern Group $(\mathrm{N}=50)$} & \multicolumn{2}{|c|}{ Central Group $(\mathrm{N}=60)$} & \multicolumn{2}{|c|}{ Western Group $(\mathrm{N}=36)$} \\
\hline & $f_{I}$ & $\%$ & $f_{i}$ & $\%$ & $f_{i}$ & $\%$ & $f_{i}$ & $\%$ \\
\hline $\mathrm{H}$ & 47 & 32.19 & 15 & 30 & 24 & 40 & 8 & 22.22 \\
\hline I & 3 & 2.05 & & & 3 & 5 & & \\
\hline $\mathrm{J}$ & 8 & 5.48 & 5 & 10 & 3 & 5 & & \\
\hline $\mathrm{J} 1$ & 1 & 0.68 & 1 & 2 & & & & \\
\hline $\mathrm{J} 1 \mathrm{a}$ & 2 & 1.37 & 1 & 2 & 1 & 1.67 & & \\
\hline $\mathrm{J} 1 \mathrm{~b} 1$ & 3 & 2.05 & & & 3 & 5 & & \\
\hline $\mathrm{J} 2$ & 1 & 0.68 & & & 1 & 1.67 & & \\
\hline $\mathrm{L} 1 \mathrm{c}$ & 1 & 0.68 & & & 1 & 1.67 & & \\
\hline $\mathrm{L} 2$ & 2 & 1.37 & 2 & 4 & & & & \\
\hline L3e $2 b$ & 1 & 0.68 & 1 & 2 & & & & \\
\hline M1 & 4 & 2.74 & 1 & 2 & 1 & 1.67 & 2 & 5.56 \\
\hline N1b & 2 & 1.37 & 1 & 2 & 1 & 1.67 & & \\
\hline $\mathrm{T}$ & 3 & 2.05 & & & 3 & 5 & & \\
\hline $\mathrm{T} 1$ & 3 & 2.05 & 1 & 2 & & & 2 & 5.56 \\
\hline $\mathrm{T} 2$ & 9 & 6.16 & 3 & 6 & 4 & 6.67 & 2 & 5.56 \\
\hline T3 & 6 & 4.11 & 1 & 2 & 2 & 3.33 & 3 & 8.33 \\
\hline \multicolumn{9}{|l|}{$\mathrm{U}$} \\
\hline U2 & 1 & 0.68 & & & & & 1 & 2.78 \\
\hline U3 & 2 & 1.37 & 2 & 4 & & & & \\
\hline U5 & 2 & 1.37 & 2 & 4 & & & & \\
\hline $\mathrm{U} 5 \mathrm{a} / \mathrm{b}$ & 3 & 2.05 & 3 & 6 & & & & \\
\hline U5a1a & 2 & 1.37 & 1 & 2 & 1 & 1.67 & & \\
\hline U5b & 1 & 0.68 & 1 & 2 & & & & \\
\hline U6a & 3 & 2.05 & 3 & 6 & & & & \\
\hline U6b & 2 & 1.37 & & & & & 2 & 5.56 \\
\hline K & 8 & 5.48 & 3 & 6 & 4 & 6.67 & 1 & 2.78 \\
\hline pre-HV & 1 & 0.68 & & & 1 & 1.67 & & \\
\hline pre*V & 2 & 1.37 & & & & & 2 & 5.56 \\
\hline V & 15 & 10.27 & 1 & 2 & 2 & 3.33 & 12 & 33.33 \\
\hline W & 3 & 2.05 & 1 & 2 & 2 & 3.33 & & \\
\hline$X$ & 4 & 2.74 & 1 & 2 & 2 & 3.33 & 1 & 2.78 \\
\hline $\mathrm{R}^{*}$ & 1 & 0.68 & & & 1 & 1.67 & & \\
\hline
\end{tabular}

\section{HVRI Diversity}

Table 4 presents diversity parameters for the Azorean population and populations cited in Table 1, obtained using HVRI sequences between positions 1606916370. In the total Azorean sample, 80 different HVRI lineages, characterised by 74 polymorphic sites, were observed. The highest values of diversity estimators were obtained for the Central and Eastern group, with similar values, and the lowest values were observed in the Western group. Compared to other populations, the values for mean numbers of pairwise differences $\left(\theta_{\pi}\right)$ and nucleotide diversity $(\pi)$ were higher than the majority of European populations in the Azores sample (total or by groups of islands). A median value of gene diversity was observed in the Azores. However, the value registered for the Western group appears to be one of the lowest when the three groups of islands were analysed separately. The values of diversity decreased in the three groups of islands when African sequences (L1, L2, L3 and M1) were excluded (Table 4).

The analysis of diversity by haplogroups in the Azorean sample compared to mainland Portugal (Table 5) showed high values of diversity for the haplogroups $\mathrm{U}$ and $\mathrm{J}$, while the diversity of the remaining 


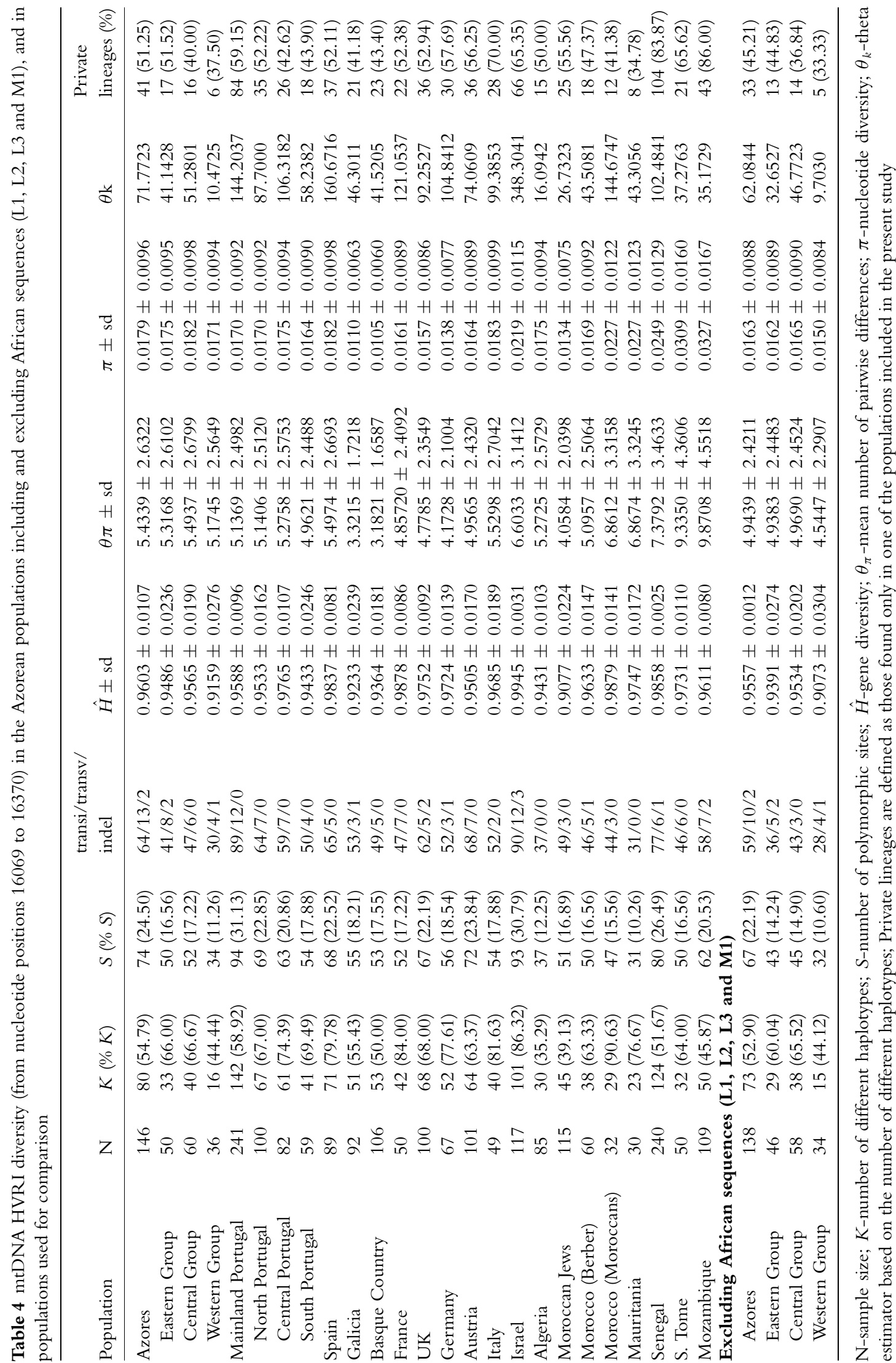




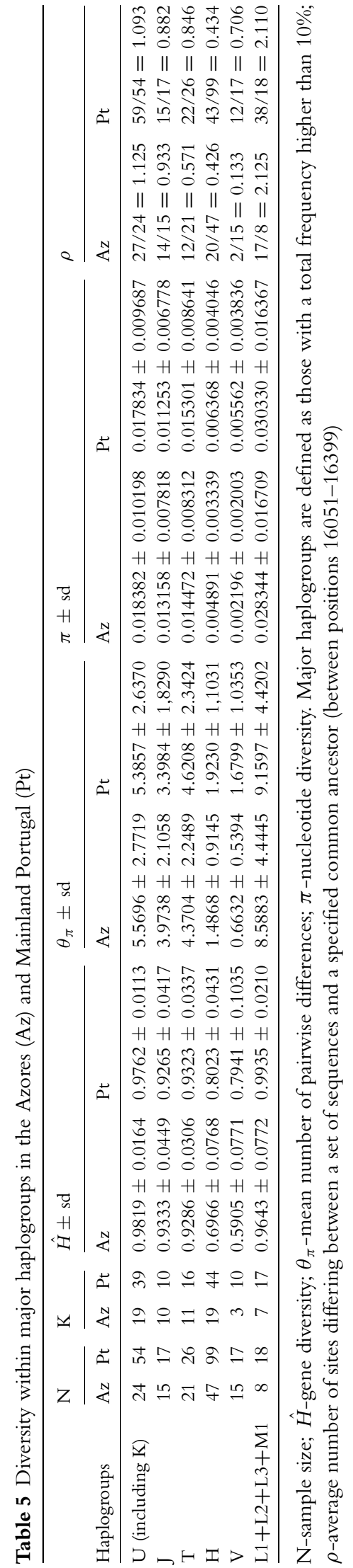

haplogroups is lower in the Azores. In the Azorean sample, $\mathrm{H}$ and $\mathrm{V}$ haplogroups present the lowest values of diversity. The African haplogroups have high values of $\theta_{\pi}, \pi$ and $\rho$, followed by the $\mathrm{U}$ haplogroup. However, in the Azores, the highest value for gene diversity is displayed by haplogroup $U$.

Relating gene diversity and nucleotide diversity in the three groups of islands (Table 4) to intra-haplogroup variation (Table 5), it is possible to infer that the higher nucleotide diversity observed in the Azores, as compared to European populations, is mainly the result of the presence of African sequences in the three groups of islands. Nevertheless, the influence of the variability of some specific haplogroups, especially $\mathrm{U}$, also has some influence on the increase in both nucleotide and gene diversity.

According to Helgason et al. (2000), the theta estimator based on the number of different haplotypes $\left(\theta_{\mathrm{k}}\right)$ is likely to provide a more reliable evaluation of current and historical female effective-population size than $\theta_{\pi}$. Of all the populations studied, the Western group presents the lowest value of $\theta_{\mathrm{k}}$, and the Central and Eastern groups also presented relatively low values (Table 4). This indicates that the Azores, and especially the Western group, have recently had a relatively small female effective-population size.

In general, the proportion of private lineages sampled from geographical proximate populations should increase as a function of $\theta_{\mathrm{k}}$, as this parameter reflects the probability of new lineages arising by mutation (Helgason et al. 2001). High values of private lineages associated with low values of $\theta_{\mathrm{k}}$, found in some populations used in the comparison such as Mozambique, are the result of the non-inclusion of a sufficient number of geographically related populations in the comparative database to detect gene flow. Considering the analysis of European populations alone, a significant positive correlation is observed between the percentage of private lineages and the values of $\theta_{\mathrm{k}}\left(r_{s p}=\right.$ 0.596; $\mathrm{p}=0.009)$. The relationship between the percentage of private lineages and the values of $\theta_{\mathrm{k}}$ is presented in Figure 1, and varies greatly among the three groups of islands. The Eastern group presents an excess of private lineages in contrast to the Central group, which tends to a scarcity of private lineages. The western group, and the total sample of the Azores, have a 


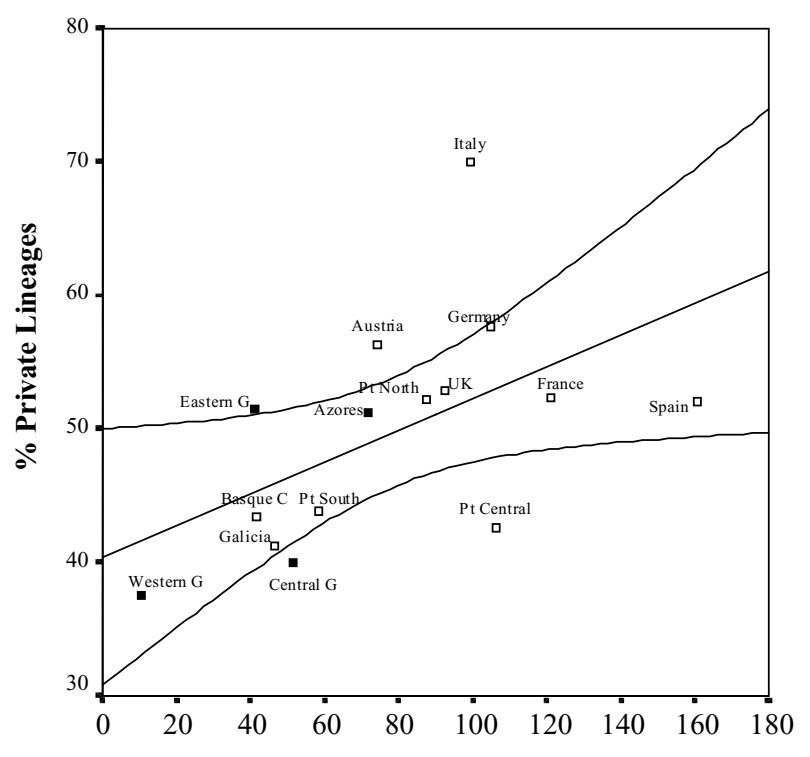

$\theta_{\mathrm{k}}$

Figure 1 Scatterplot of $\theta_{\mathrm{k}}$ values and percentage of private lineages. The least-squares regression line is shown. The curved lines show the $95 \%$ confidence region around the regression line.

proportion of private lineages that can be expected by their $\theta_{\mathrm{k}}$.

The excess of private lineages observed in the Eastern group could have different causes. An intuitive explanation is that the isolation of the islands can hinder the migratory flow of new lineages to and from neighbouring populations. However, six of the private lineages found in the Eastern group belong to African clusters (U6a, M1, L2 and L3). Consequently, it is more likely that a sufficient number of African populations was not included in the comparative database.

Within the Azores, the Central group shares the highest number of lineages with the other two groups of islands. Therefore, the relative scarcity of private lineages observed in the Central group could be indicative of either a very high level of emigration (where few lineages remain private for long, because of rapid outward gene flow to neighbouring populations), or of immigration (where new lineages arriving into the population would increase $\theta_{\mathrm{k}}$ but not the proportion of private lineages).

The values of diversity parameters, reported for the archipelago, allow us to infer that the Azores population as a whole does not present the typical characteris- tics of an isolated population. Thus, the values recorded are similar to those observed in the majority of European populations used in the comparative analysis, and higher than those observed in isolated populations like the Basque country and Galicia. Furthermore, neither an excess nor a scarcity of private lineages is observed, in relation to the respective $\theta_{\mathrm{k}}$ value, suggesting that values of diversity in the Azores are adjusted to the effective population size of females.

These results are in accordance with studies of autosomal STRs (Lima, personal communication), classical markers (Amorim et al. 1979) and those reported in biodemographic studies, which indicate that the Azorean archipelago, when considered as a whole, does not exhibit levels of endogamy and consanguinity higher than those reported for some populations from mainland Portugal (Cunha, 1987; Lima, 1991; Lima \& Soares, 1992; Smith et al. 1992).

When analyses were carried out by groups of islands, the Western group appears to have different features. The haplogroup distribution is very atypical, diversity values are in general lower than those observed in the other groups of islands, and the value of gene diversity is one of the lowest registered in all of the populations used for comparison. However, the relationship between the percentage of private lineages and values of $\theta_{\mathrm{k}}$ indicate that this group of islands does not undergo a higher level of isolation than that observed in the other groups of islands. This leads to the conclusion that the observed haplogroup distribution and lower diversity are strictly related to the reduced number of females present in the island since peopling, and makes the roles of founder effect and genetic drift in small populations evident.

\section{Phylogeography of Azores mtDNA}

Figure 2 (a, b, c, d, e) represents phylogenetic networks of haplotypes found in the Azores and populations used for comparison. To simplify networks, haplotypes absent in the Azores were only represented if they were phylogenetically related to haplotypes present in the Azorean population. Examining the networks, from the 80 different haplotypes (based on HVRI information) found in the Azores, only six are present in more than one group of islands. Two haplotypes are present in the three groups, three are common to the Central and Eastern 


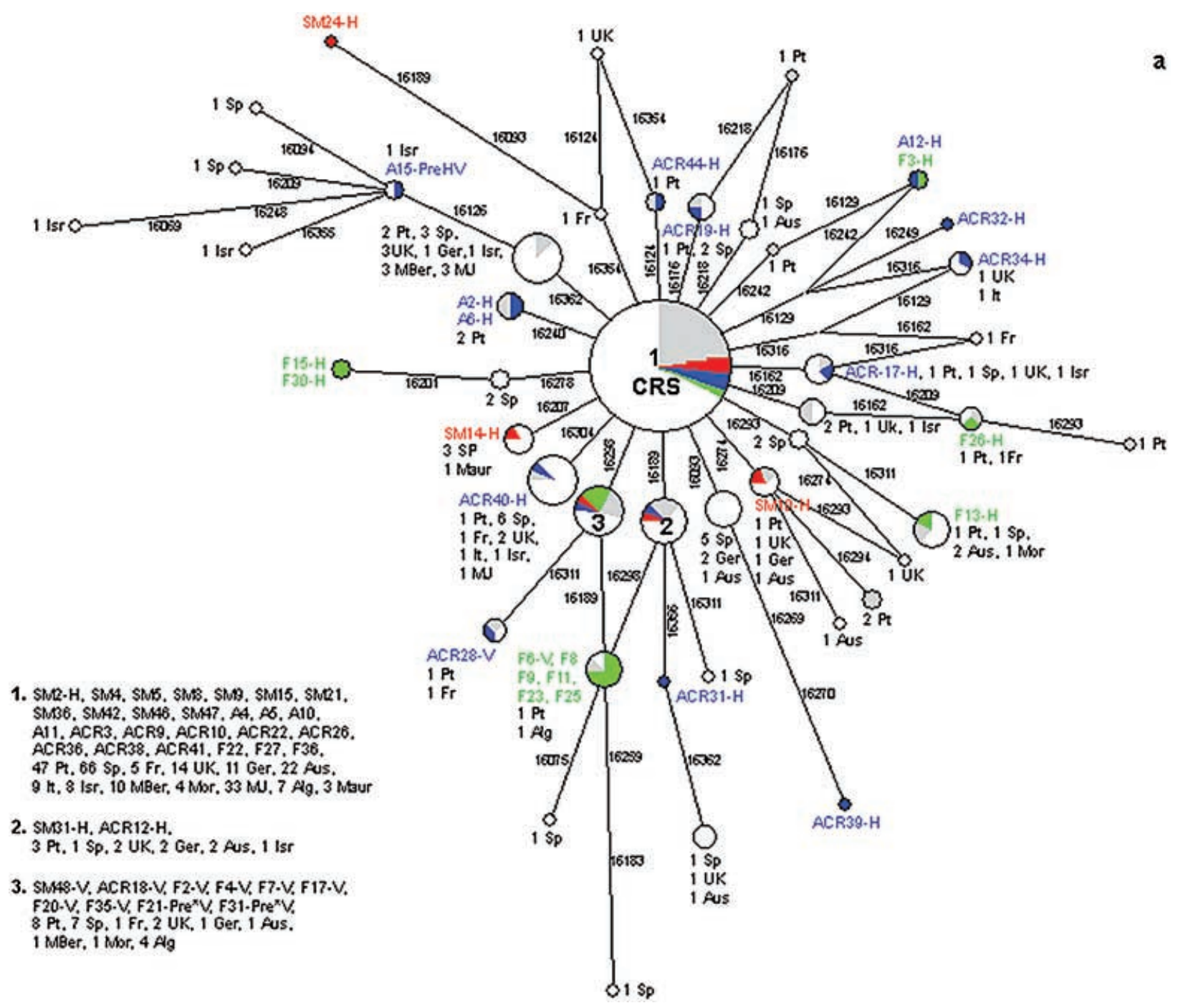

Figure 2 Phylogenetic Networks of (a) H, V, HV, Pre-HV, Pre*V; (b) U (including K); (c) J, T, JT; (d) N, I, W, X; (e) L1, L2, L3, M. Circle sizes are proportional to the haplotype frequency. (Red - Eastern group; Blue - Central group; Green - Western group; Gray - Mainland Portugal; White - other populations).

groups, and one to the Central and Western groups. The Central group is the one that shares the highest number of haplotypes with the other two. This result indicates limited migratory movements among the three groups of islands, until at least the beginning of the $19^{\text {th }}$ century (since the geographical location of the sample was based on the origin of the great-grand-parents of the donor).

Forty-one haplotypes (represented in the networks as single colour circles: red to the Eastern group, blue to the Central group and green to the Western group) appear to be exclusive to the Azores, and thirty-nine are shared with other populations. By analysing the shared haplotypes, thirty-three were found to be common to the Iberian Peninsula (mainly to mainland Portugal). However, only eleven are shared exclusively with the Iberian Peninsula, the remaining twenty-two also being present in one or more of the other populations. Specifically, sixteen are found in other European populations, ten in Israel, five in Moroccan Jews, eleven in North Africa and four in West Africa. Considering that these haplotypes belong to European haplogroups $(\mathrm{H}, \mathrm{J}, \mathrm{T}$ U, K, V and X) (Torroni et al. 1996) their most probable origins are the Iberian Peninsula or other European populations. However, a possible North African origin cannot be excluded for some sequences. The work of 


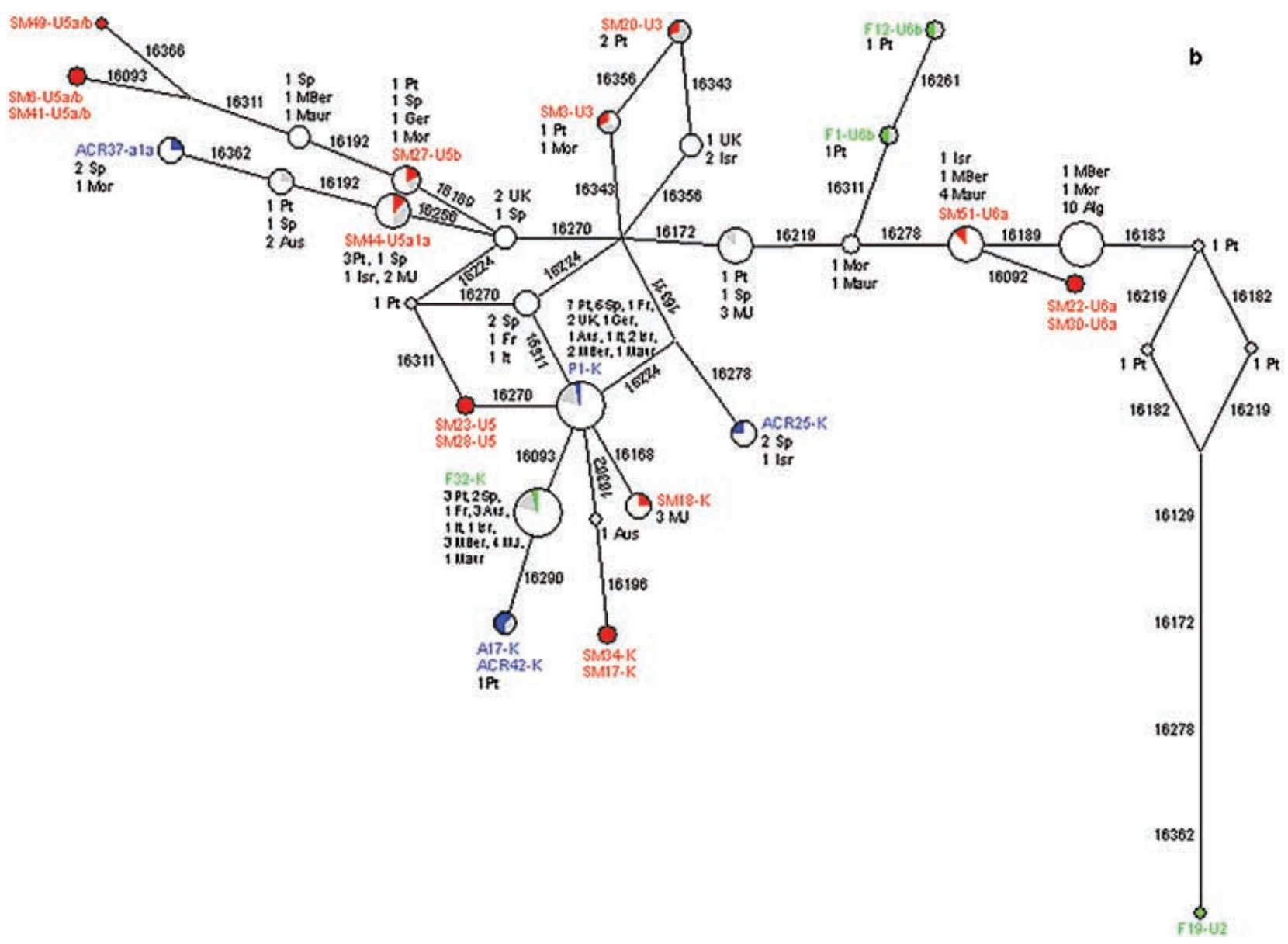

Figure 2 (continued)

Rando et al. (1998) attests to the fact that there is strong evidence for some degree of European genetic input into North Africa. There is, for example, evidence that haplogroups U5 (Richards et al. 1998) and V (Torroni et al. 1998) are represented in North Africa. Only one haplotype (ACR34-H) is shared exclusively with nonIberian European populations (Fig. 2a).

Haplotypes represented by A15-pre-HV (Fig. 2a) and SM11-N1b (Fig. 2d) are shared exclusively with the Israeli population, and SM18-K (Fig. 2b) with Moroccan Jews. Taking into account the fact that the Israel Arab/Palestinian sample represents an extant population living in the region to which Jews trace their origin (Thomas et al. 2002), and that Moroccan Jews probably included descendants of the Sephardim Jews that were expelled from the Iberian Peninsula, the three haplotypes (represented by A15, SM11 and SM18) previously mentioned could indicate the presence of Sephardim Jews in the Azores. The haplotype represented by SM51
(Fig. 2b), belonging to sub-haplogroup U6a, is shared with Israeli and North African populations. This haplotype is probably originally from North Africa, since the U6 haplogroup has been described as a North African cluster (Rando et al. 1998).

U6 sequences are represented in both the Eastern and Western groups; however, in the Western group (samples F1, F12) they belong to sub-cluster U6b, which, according to Plaza et al. (2001), is restricted to the Iberian Peninsula. In the Eastern group (samples SM22, SM30 and SM51) they are assigned to U6a, found in both the Iberian Peninsula and North Africa (Plaza et al. 2001; Rando et al. 1998). Thus, only lineages found in the Eastern group could plausibly constitute evidence of the influence of Moorish slaves, which is in accordance with historical data.

The haplotype represented by A16 (Fig. 2d), a member of the European haplogroup I, is present in nonIberian European populations. In S. Tome, the same 


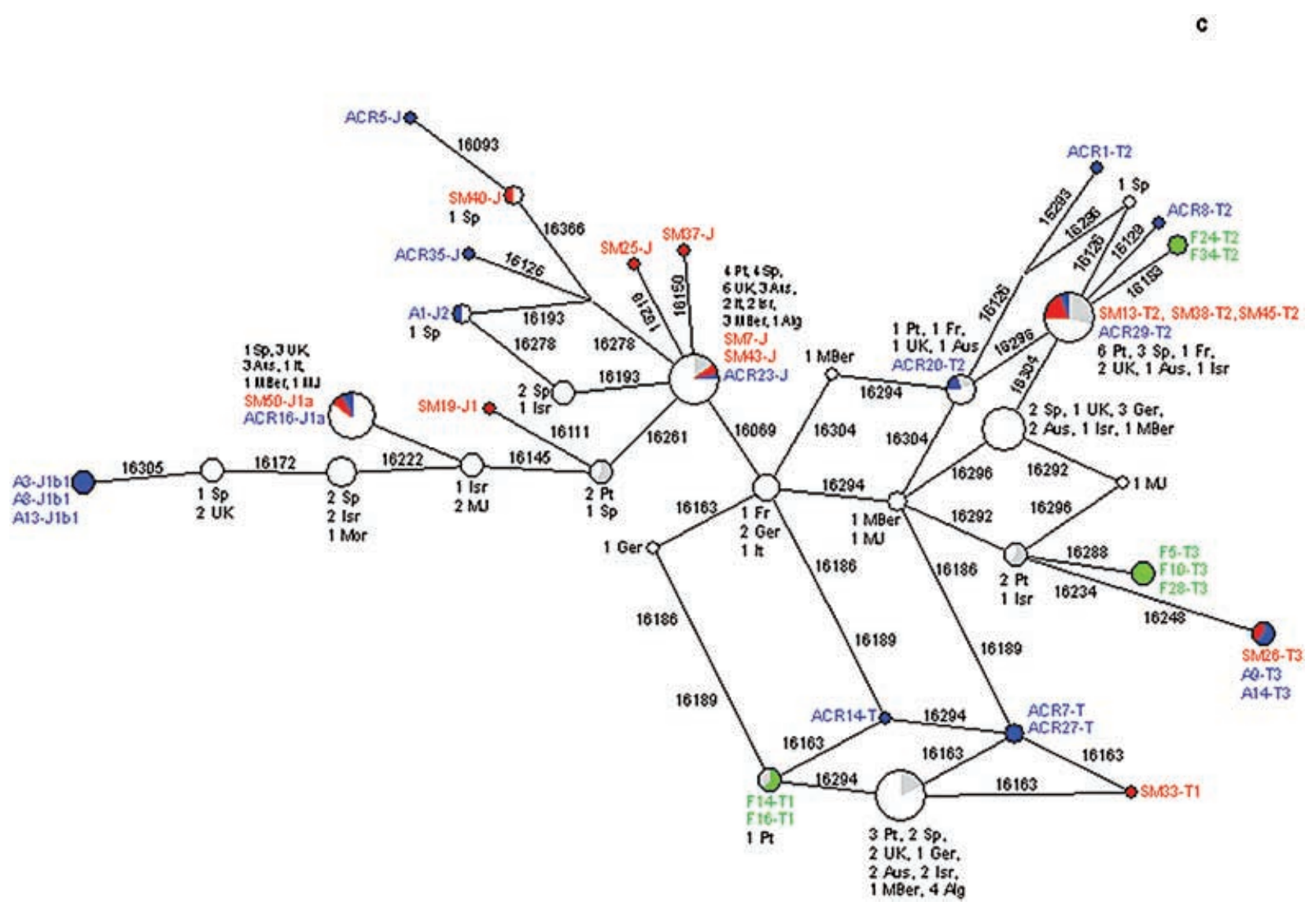

Figure 2 (continued)

haplotype was found (Mateu et al. 1997); however that sample probably belongs to haplogroup L3 (Calafell, Comas \& Mateu, personal communication).

In summary, the analysis of shared haplotypes indicates that the majority of haplotypes is shared with Iberian Peninsula populations, principally with mainland Portugal. A small influence from other European (especially North European), Near East/Jewish and North African populations can also be confirmed.

The 41 private lineages found could have been introduced into the Azores both by European and by African individuals belonging to populations that are not included in the comparison, for example, populations from Flanders and Madeira Island, for which data are not available. Alternatively, as suggested by Helgason et al. (2000), they may arise from populations included in the analysis in which these lineages have not yet been sampled, or have been lost since the inhabitation of the Azores.
On the other hand, the hypothesis of the origin of some private lineages in recent mutational events occurring after the settlement of the islands cannot be disregarded.

The possible origin of the non-shared haplotypes, to be discussed later, was inferred using the partial networks presented in Figure 2 and two mtDNA databases, namely the database of Richards et al. (2000) and the HVRbase (Handt et al. 1998), both available online.

A worldwide search for the 41 private haplotypes found in the Azores was performed in mtDNA databases, and eight matches with samples that were not included in the comparison were found. Haplotypes represented by ACR31-H (Fig. 2a), F24-T (Fig. 2c), ACR30-W (Fig. 2d) and SM49-U5a/b (Fig. 2b) are shared with Northern European populations that were not included in the analysis; ACR8-T2 (Fig. 2c), SM12-X (Fig. 2d) and ACR7-T (Fig. 2c) match with one sequence each, found, respectively, in Rome (Italy), Romany and Armenia; SM22 (Fig. 2b), which 


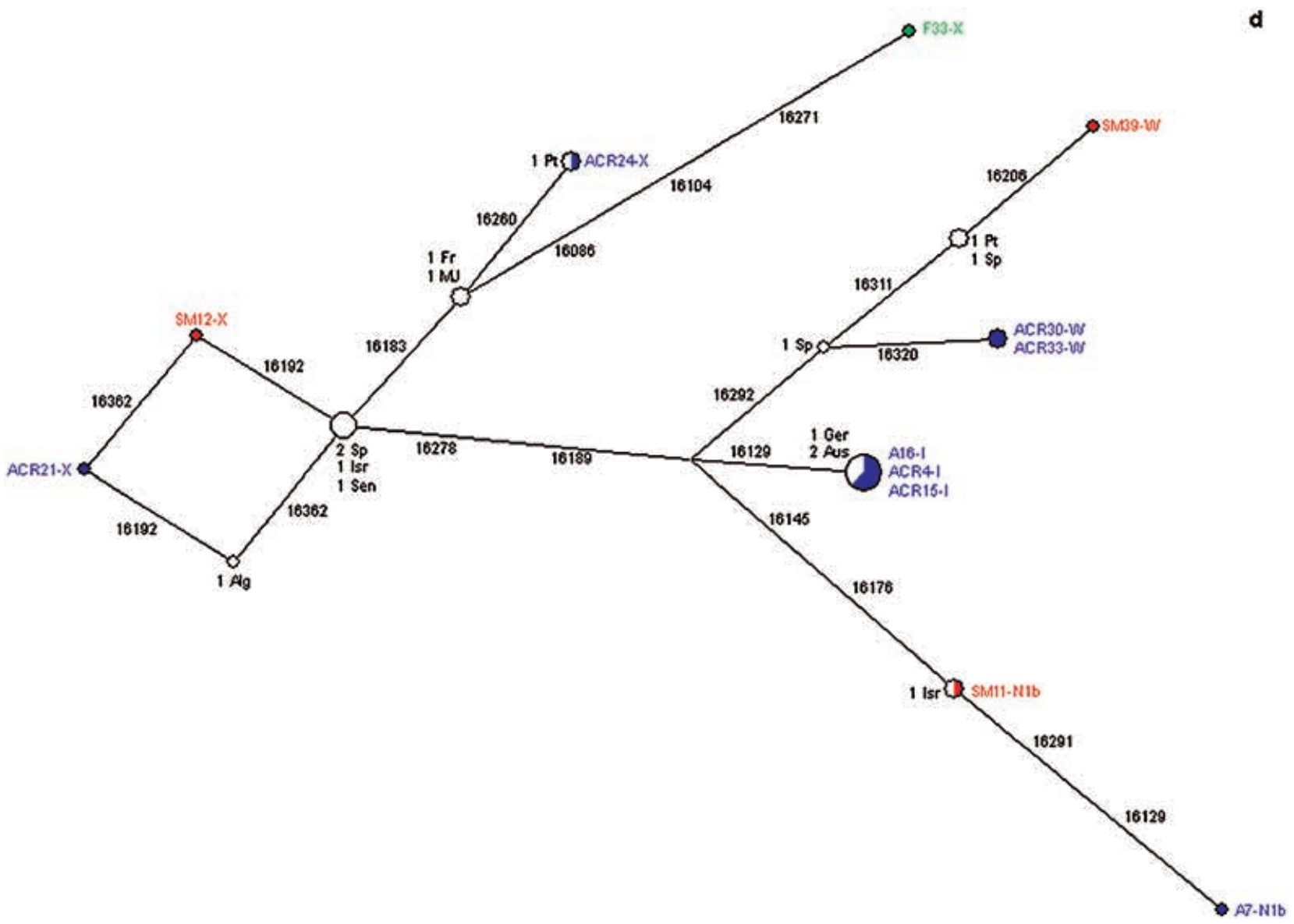

Figure 2 (continued)

belongs to the North African cluster U6a (Rando et al. 1998), is not shared with populations used for comparison, but was found in the Canary Islands (Rando et al. 1999) and in Moroccan Berbers (Anglés, personal communication).

Haplotypes classified as J can provide valuable information for the inference of the origin of the Azorean population. This haplogroup is present at high frequencies in Northern European populations, and some specific clusters, such as J1b1, can be assigned to a very restricted geographic area. Haplogroup $\mathrm{J}$ is absent in the Western group, but its frequency is close to $14 \%$ in both the Eastern and Central groups, higher than that observed in the Iberian Peninsula and similar to that observed in Northern European populations. Among the ten $\mathrm{J}$ haplotypes found in the Azores, six are private lineages (Fig. 2c).

The haplotype represented by ACR 5 could have been derived from the haplotype 16069, 16126, 16278,
16366, found in mainland Portugal and in the Eastern group (SM40). SM19 could have been derived from the haplotype 16069, 16126, 16261, found in mainland Portugal. Haplotypes represented by SM25 and SM37 could be derived from haplotype 16069, 16126 found in the Azores (SM7, SM43 and ACR23) and at high frequencies in Europe, especially in United Kingdom. Haplotype A3 was possibly derived from the haplotype $16069,16126,16145,16172,16222,16261$, found in the United Kingdom and Spain.

Nevertheless, other origins can be postulated for the previously mentioned J haplotypes. Importantly, the influence of the population from the region of Flanders that was not included in the analysis is always mentioned in the peopling of the Central group. It is expected that this population, like the surrounding Northern European populations, would have high frequencies of haplogroup J, and some of the non shared haplotypes found in the Azores could match with those which, 


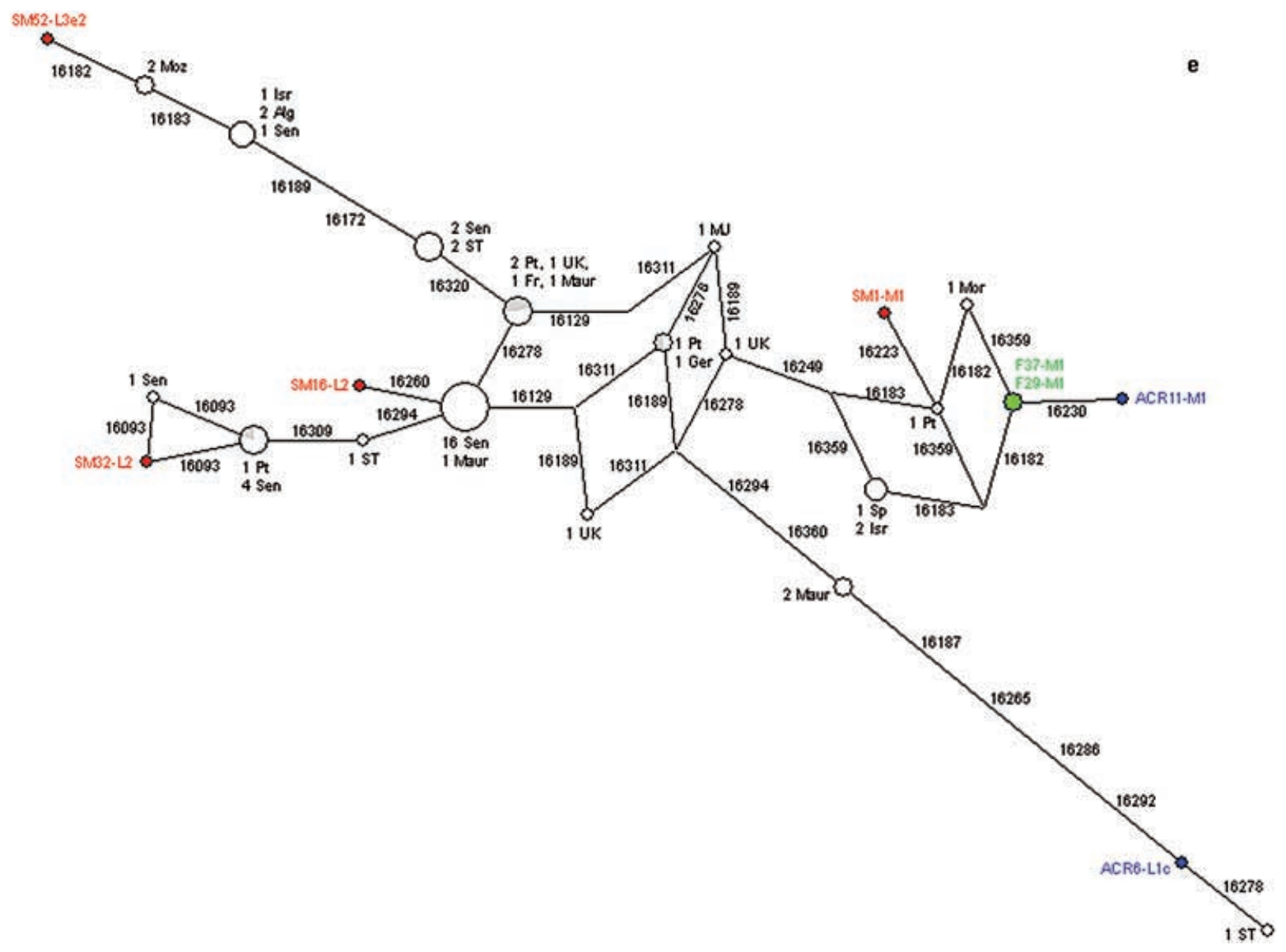

Figure 2 (continued)

hypothetically, would be found if the mtDNA of Flemish populations was analysed.

East African M1 sequences (SM1, ACR11, F29 and F37) (Fig. 2e) do not match any sequence present in the mtDNA databases, probably because African populations are less studied. The most similar sequence that was found is a North African sequence with the motif 16129, 16182C, 16183C, 16189, 16223, 16249, 16311. All the M1 sequences found in the Azores have a very similar motif, and probably trace their origin to the same geographical region in East Africa. With respect to L1, L2 and L3 sequences (Fig. 2e), they are located in the network near to sequences from various sub-Saharan populations and from mainland Portugal African sequences. This indicates a common origin for both African sequences present in mainland Portugal and the Azores islands, which is consistent with the historical context of the $16^{\text {th }}$ century, when Portugal was actively involved in the slave trade (Thomas, 1998).
The analysis of non-shared haplotypes indicates that the majority of the European private lineages have their probable origin in Northern European and Near Eastern populations. Evidence of influences from both North Africa and sub-Saharan Africa were found in the Azores; however, a strict geographic origin for African sequences is difficult to define.

The terminal position in the networks of several Azorean haplotypes, and their strict relation with other Azorean haplotypes, seem to indicate that some of the private lineages could have originated in the Azores.

\section{Estimates of Admixture}

To estimate the proportion of admixture, the information concerning the possible origin of both shared and non-shared haplotypes was summarised. Three major groups were defined for the origin of mtDNA in the Azores (Europe, Near East and Jews, and Africa). 


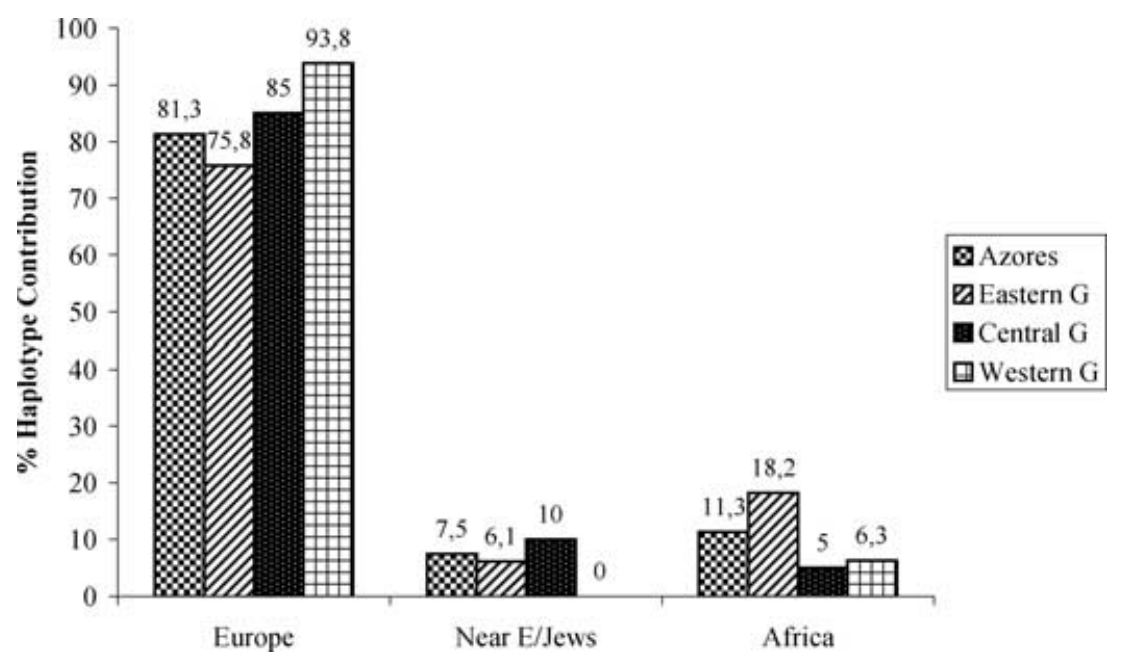

Figure 3 Bar chart showing the pattern of haplotype contribution from parental populations to the Azores.

Whenever a haplotype is shared with a European population, it is admitted that its most probable origin is Europe. Thus, it is possible to infer that probably: a minimum of $11.25 \%$ of the haplotypes found in the Azores are originally from African populations; a minimum of $7.5 \%$ are derived from Near Eastern and Jewish populations; and a maximum of $81.25 \%$ are from European populations.

Figure 3 illustrates the observation that mtDNA gene pools of all the groups of islands have their major contribution from European populations. However, there are some differences among the three groups of islands. The Eastern group exhibits the highest contribution from non-European populations (close to $25 \%$ ), mainly African (18.2\%), revealing the influence of slaves in the peopling of this group of islands.

In the Central group, the non-European influence is approximately $15 \%, 10 \%$ from Near Eastern/Jewish populations, and 5\% from African populations. The Western group exhibits the lowest contribution of nonEuropean lineages (6.25\%), which is exclusively African. According to historical information the contribution of slaves to the peopling of the islands, mainly to the Eastern and Western groups, was very important, being well-documented for the Western group (for review see Gomes, 1997). One of the headmen of Flores island was also leader of Santo Antão island (Cabo Verde), and a great number of the slaves who arrived at the Western group were originally from Cabo Verde. Surprisingly, no L1, L2 or L3 mtDNA lineages were found in the Western group. This indicates that factors such as differential mortality may have affected the fitness of slaves, limiting the transmission of their genes until now.

\section{Genetic Distances and Phylogenetic Reconstruction}

To examine the relationship between all pairs of populations used in the comparison, genetic distances according to Reynolds et al. (1983) were calculated, and used to build a phylogenetic tree (not shown). In contrast to European populations, African populations present higher genetic distances among themselves. This justifies the existence of an identifiable gradient observed in the N-J tree from sub-Saharan to North African populations, and the aggregation of the European populations in one extreme of the tree. It is impossible to establish any relation among European populations. Furthermore, the three groups of islands are located in this assemblage.

To try to clarify the position of the Azores with respect to other populations, various N-J trees were built. The position of the various populations was very similar in all the trees. In Figure 4, a tree that excludes Algerian and Western and Eastern African populations is shown, where the African populations that show less genetic distance relative to the Azores are maintained. 


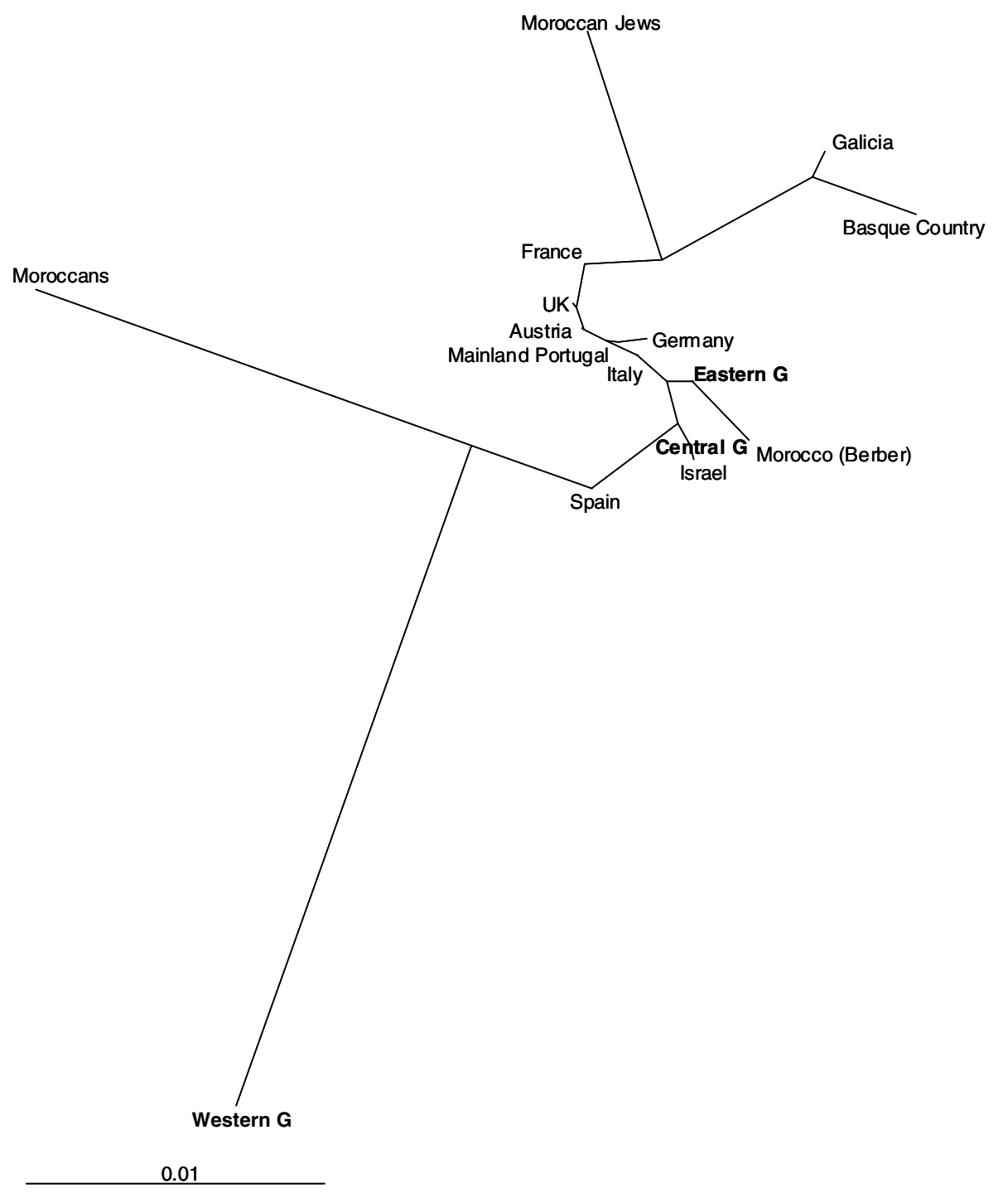

Figure 4 Neighbour-Joining tree (Saitou \& Nei, 1987) constructed from Reynolds et al. (1983) genetic distances.

The analysis of Figure 4 reveals that the geographically and/or culturally isolated populations, such as those of the Basque Country, Galicia and Moroccan Jews, are separated from the remaining European populations. Moroccans also appear to be separated, because this population is the most differentiated relative to European populations. The three groups of islands are located in different branches of the tree that emerge from a group of European populations. However, the Western group appears in a very profound and isolated branch, reinforcing the previous results that indicate a differentiation of this group of islands. The Central group is located in the same branch as Israel, while the Eastern group is posi- tioned in the same branch as the Moroccan Berbers. The position of the Eastern group corroborates previous results, indicating some affinities with African populations. In a similar manner the position of the Central group indicates that there is some relationship with Near Eastern populations.

The analysis of phylogeography of Azores mtDNA, estimates of admixture, genetic distances and phylogenetic reconstruction allow us to infer a possible origin for the mtDNA gene pool of the Azores. All the analyses support the idea that, in all the groups of islands, the majority of mtDNA lineages come from the Iberian Peninsula, mainly from Portugal, but the contribution 
of other European populations, especially from Northern Europe, cannot be disregarded. The presence of Moorish and African slaves in the islands is also supported by mtDNA genetic data, especially in the Eastern group, as well as the presence of Jews, mainly in the Central group.

Neither historical nor genetic data supports the idea of a differential settlement for the Western group; however, it appears in the phylogenies in an isolated branch. With 4329 inhabitants (INE, 2001) today, the Western group has reduced its population size by half in less than one century. Thus, this "bottleneck", combined with a small population size since peopling, has led to a very atypical distribution of haplogroups/haplotypes that influences all the results obtained. Future genetic and biodemographic investigations in the Western group will certainly help to clarify its position relative to the rest of the archipelago, and to other populations.

\section{Conclusions}

This work confirms that studies of large population samples in restricted geographical contexts can produce valuable insights concerning specific genetic and demographic features that would remain undetectable in broad scale surveys.

The distinct analyses allow us to infer that the Azorean population does not present the typical characteristics of an isolated population, as is usually postulated for islands. However, the Azores archipelago has a recent demographic history, was peopled by individuals of multiple origins, which naturally leads to a population with high diversity, and it is probable that the effect of isolation, if it exists, remains undetectable at this time.

Separate analyses of the three groups of islands appeared to be valuable for detecting the specific features of the Western group, which presents some differentiation with respect to the other groups of islands. This differentiation should be the result of genetic drift processes, induced by the small population size since peo- pling, and eventually the result of the recent reduction in population size.

The analysis of lineage sharing supports the idea that mainland Portugal and Northern European populations could have contributed the majority of the mtDNA lineages that are currently observed in the Azorean mtDNA gene pool. However, many lineages are still private to the Azores, and their origins are sometimes difficult to infer, since historically related populations such as the population of Flanders are not used for comparison, because they remain uncharacterised for mtDNA.

Contrary to studies using autosomal markers (Lima et al. personal communication), it was possible to infer the influence of African and Near East/Jewish individuals in the islands, pointing out the effectiveness of non-recombining markers to reconstruct the history of populations. It was even possible to detect differential contributions of non-European populations to the peopling of the three groups of islands, mainly the contribution of Africans to the Eastern group, and the contribution of Near East/Jewish to the Central group, both in accordance with historical data.

Part of the variation in the Azorean mtDNA can be explained by the settlement history of the archipelago. Furthermore, it has been necessary to bear in mind that the variation of mtDNA was affected during the last 500 years, by biodemographic and genetic processes like founder effect, genetic drift, migration, and even recent mutational events. Thus, the results presented here arise from the combination of the history of peopling and the evolution of populations, with all their biodemographic and genetic interactions.

\section{Acknowledgments}

This work was supported by a grant (ref. SFRH/BD/ 723/2000) from Fundação para a Ciência e a Tecnologia Operational programs Science Technology and Innovation (POCTI) and Society of Information (POSI) financed by UE founds and national founds of MCES. 


\section{Santos et al.}

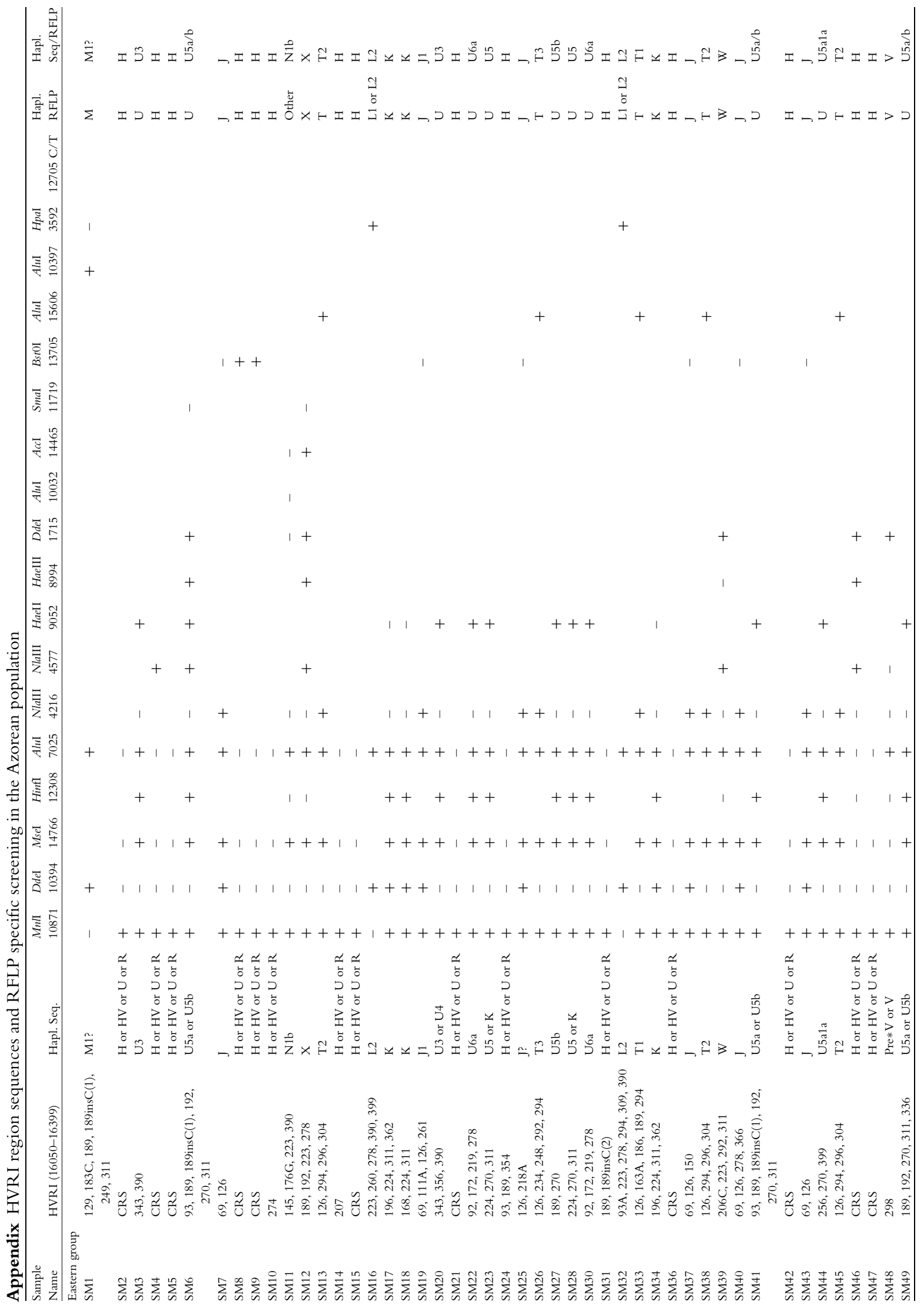




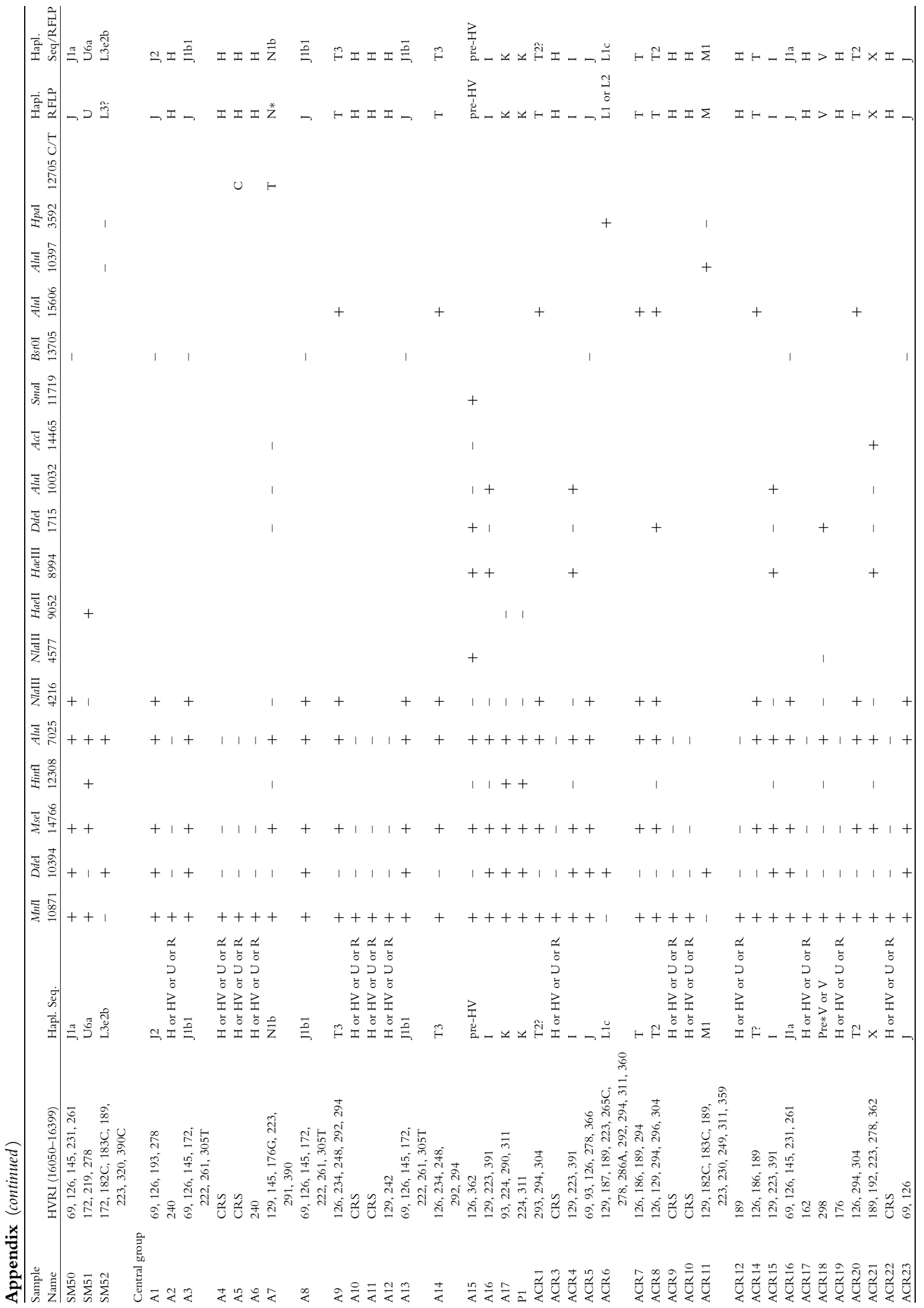




\section{Santos et al.}

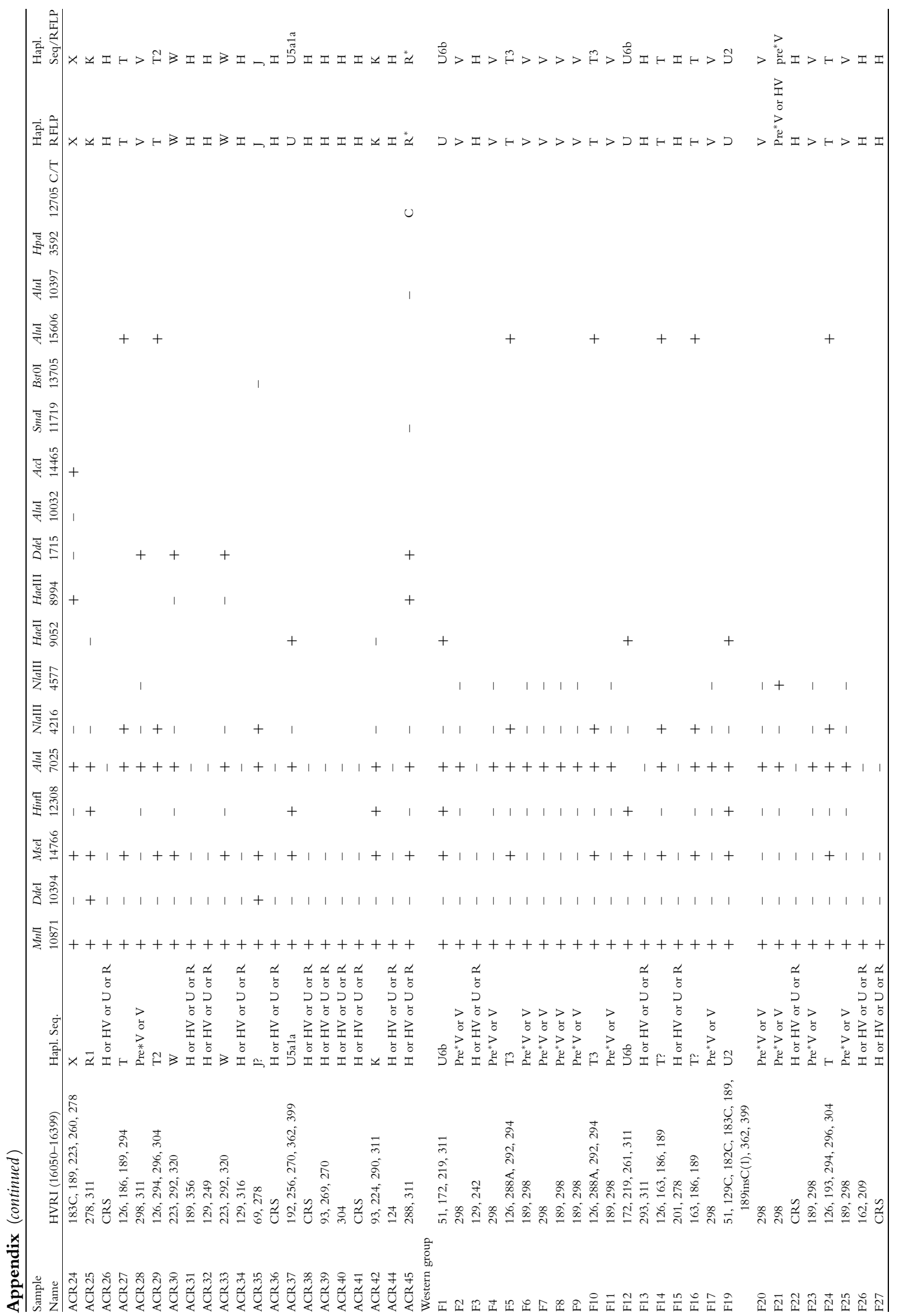




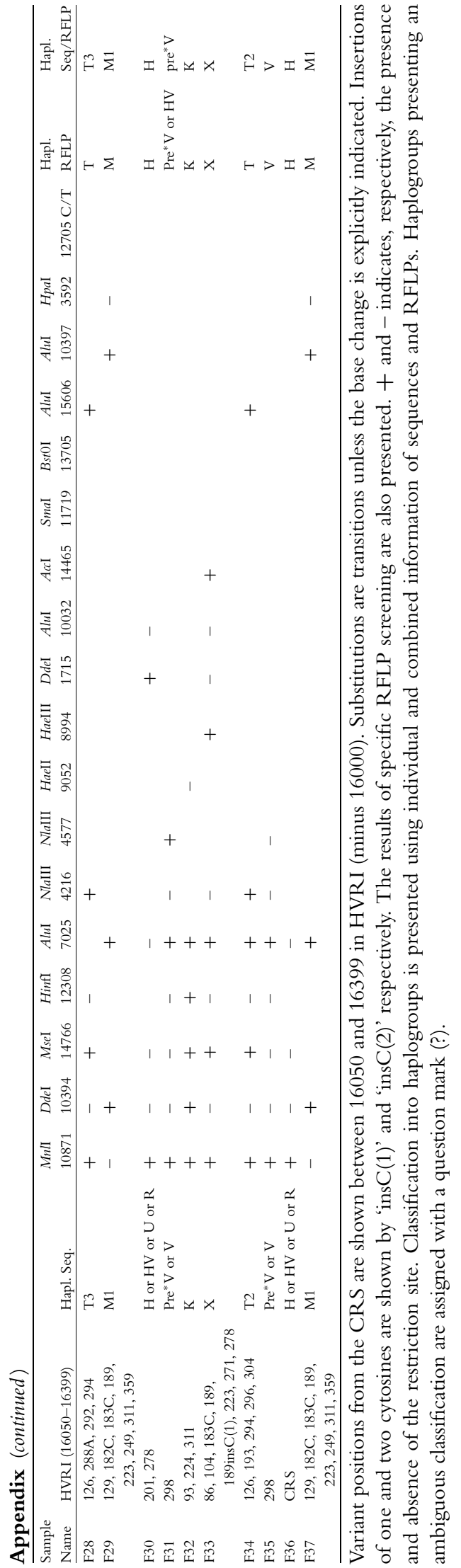

\section{References}

Amorim, A., Faria, A. S. N. \& Pereira, E. L. (1979) Red Cell Acid Phosphatase $\left(\mathrm{ACP}_{1}\right)$ Polymorphism in Flores Island (Azores). Trabalhos do Instituto de Antropologia "Dr. Mendes Corrêa”. 35, 1-4.

Anderson, S., Bankier, A., Barrell, M., Bruijn, M. H. L., Coulson, A. R., Drouin, J., Epcron, I. C., Nicrlich, D. P., Roc, B. A., Sanger, F., Chreier, P. H., Smith, A. J. H., Standen, R. \& Young, I. G. (1981) Sequence and organization of the human mitochondrial genome. Nature 290, 457-464.

Bandelt, H.-J., Forster, P. \& Röhl, A. (1999) Median-joining networks for inferring intraspecific phylogenies. Mol Biol Evol 16, 37-48.

Bertranpetit, J., Sala, J., Calafell, F., Underhill, P. A., Moral, P. \& Comas, D. (1995) Human mitochondrial DNA variation and the origin of Basques. Ann Hum Genet 59, 63-81.

Chen, Y. S., Olckers, A., Schurr, T., Kogelnik, A. M., Huoponen, K. \& Wallace, D. C. (2000) MtDNA variation in the south African Kung and Khwe and their genetic relationships to other African populations. Am J Hum Genet 66, 1362-1383.

Chen, Y. S., Torroni, A., Excoffier, L., SantachiaraBenerecetti, A. S. \& Wallace, D. C. (1995) Analysis of mtDNA variation in African population reveals the most ancient of all human continent-specific haplogroups. Am J Hum Genet 57, 133-149.

Côrte-Real, H., Macaulay, V., Richards, M., Hariti, G., Issad, M. S., Cambon-Thomsen, A., Papiha, S., Bertranpetit, J. \& Sykes, B. (1996) Genetic diversity in the Iberian Peninsula determined from mitochondrial sequence analysis. Ann Hum Genet 60, 331-350.

Cunha, E. (1987) Consanguinity of the Azores Islands (19791985). Antropologia Portuguesa 4/5, 67-79.

Di Rienzo, A. \& Wilson, A. C. (1991) Branching pattern in the evolutionary tree for human mitochondrial DNA. Proc Natl Acad Sci USA 88, 1597-1601.

Ewens, W. J. (1972) The sampling theory of selectively neutral alleles. Theor Popul Biol 3, 87-112.

Felsenstein, J. (1995) PHYLIP (Phylogeny Inference Package) ver 3.57c. Department of Genetics. University of Washington, Seattle.

Forster, P., Harding, R., Torroni, A. \& Bandelt, H.-J. (1996) Origin and evolution of Native Americans mtDNA variation: a reappraisal. Am J Hum Genet 59, 935-945.

Francalacci, P., Bertranpetit, J., Calafell, F. \& Underhill, P. A. (1996) Sequence diversity of the control region of mitochondrial DNA in Tuscany and its implications for the peopling of Europe. Am J Phys Anthropol 100(4), 443-460.

Francalacci, P., Montiel, R. \& Malgosa, A. (1999) A mitochondrial DNA database - applications to problems of nomenclature and population genetics. In: Genomic 
Diversity: Applications in Human population genetics (eds. S. S. Papiha R. Deka \& R. Chakraborty), pp. 103-119. Kluwer Academic/Plenum Publishers, New York.

Gomes, F. (1997) A ilha das Flores: da redescoberta à actualidade (subsídios para a sua história). Câmara Municipal de Lajes das Flores, Azores, Portugal.

Graven, L., Passarino, G., Semino, O., Boursot, P., Santachiara-Benerecetti, S., Langaney, A. \& Excoffier, L. (1995) Evolutionary correlation between control region sequence and restriction polymorphisms in the mitochondrial genome of a large Senegalese Mandenka population. Mol Biol Evol 12, 334-345.

Hall, T. A. (1999) BioEdit: a user-friendly biological sequence alignment editor and analysis program for Windows 95/98/NT. Nucl Acids Symp Ser 41, 95-98.

Handt, O., Meyer, S. \& Haeseler, A. (1998) Compilation of Human mtDNA control region sequences. Nucleic Acids Res 26(1), 126-129.

Helgason, A., Hickey, E., Coodacre, S., Vidar, B., Stefánsson, K., Ward, R. \& Sykes, B. (2001) mtDNA and the islands of north Atlantic: estimating the proportions of Norse and Gaelic ancestry. Am J Hum Genet 68, 723-737.

Helgason, A., Siguroardóttir, S., Gulcher, J., Ward, R., Stefánsson, K. (2000) mtDNA and the origin of the Icelanders: deciphering signals of recent population history. Am J Hum Genet. 66, 999-1016.

Hofmann, S., Jaksch, M., Bezold, R., Mertens, S., Aholt, S., Paprotta, A. \& Gerbitz, K. D. (1997) Population genetics and disease susceptibility: characterization of central European haplogroups by myDNA gene mutations, correlation with D loop variants and association with disease. Hum Mol Genet 6(11), 1835-1846.

INE (2001) Estimativas de população residente 2001 aferidas para os resultados provisórios dos Censos 2001 Instituto Nacional de Estatística, Portugal.

Lima, M. (1991) Contribuição para o estudo biodemográfico da freguesia de Rabo de Peixe Provas de aptidão pedagógica e capacidade cientifica. University of the Azores, Portugal.

Lima, M. \& Soares, A. O. (1992) Níveis de consanguinidade e endogamia da população de Furnas. Antropologia Portuguesa 9-10, 33-42.

Macaulay, V. (2000) Haplogroup motifs. Retrieved October 8, 2001 from the World Wide Web: http://www.stats. ox.ac.uk/ macaulay/founder2000/motif.html

Macaulay, V., Richards, M., Hickey, E., Veja, E., Cruciani, F., Guida, V., Scozzari, R., Bonné-Tamir, B., Sykes, B. \& Torroni, A. (1999)). The emerging tree of West Eurasian mtDNAs: a synthesis of control-region sequences and RFLPs. Am J Hum Genet 64, 232-249.

Mateu, E., Comas. D., Calafell, F., Pérez-Lazaun, A., Abade, A. \& Bertranptit, J. (1997) A tale of two islands: population history and mitochondrial DNA sequence variation of
Bioko and São Tomé, Gulf of Guinea. Ann Hum Genet 61, 507-518.

Matos, A. (1989) Povoamento e Colonização dos Açores in Portugal no Mundo Publicações Alfa, Lisboa, Portugal

Mendonça, L. (1996) História dos Açores - Visão geral (sécs. $X V-X I X)$ Centro de Apoio Tecnológico à Educação, Ponta Delgada, Azores, Portugal

Montiel, R. (2001) Estudio diacrónico de la variabilidad del DNA mitocondrial en población Catalana $\mathrm{PhD}$ dissertation. Autonomous University of Barcelona, Barcelona, Spain. (http://www.tdcat.cesca.es/TDCat-0726101-095837)

Montiel, R., Malgosa, A. \& Francalacci, P. (2001) Authenticating ancient human mitochondrial DNA. Hum Biol 73(5), 689-713.

Nei, M. (1987) Molecular evolutionary genetics Columbia University Press, New York.

Page, R. (1996) Treeview: an application to display phylogenetic trees on personal computers. Comput Appl Biosci 12, 357-358.

Parson, W., Parsons, T., Scheithauer, R. \& Holland, M. M. (1998) Population data for 101 Austrian caucasian mitochondrial DNA d-loop sequences: Application of mtDNA sequence analysis to a forensic case. Int J Legal Med 111, 124-132.

Pereira, L., Macaulay, V., Torroni, A., Scozzari, R., Prata, M. J. \& Amorim, A. (2001). Prehistoric and historic traces in the mtDNA of Mozambique: insights into the Bantu expansions and the slave trade. Ann Hum Genet 65, 439458.

Pereira, L., Prata, M. J. \& Amorim, A. (2000). Diversity of mtDNA lineages in Portugal: not a genetic edge of European variation. Ann Hum Genet 64, 491-506.

Piercy, R., Sullivan, K., Benson, N. \& Gill, P. (1993) The application of mitochondrial DNA typing to the study of white Caucasian genetic identification. Int J Leg Med 106, 85-90.

Pinto, F., González, A., Hernández, M., Larruga, J. M. \& Cabrera, V. M. (1996) Genetic relationship between the Canary islanders and their African and Spanish ancestors inferred from mitochondrial DNA sequences. Ann Hum Genet 60, 321-330.

Pires, L. (1999) A Origem da população dos Açores com base em estudos de DNA mitocondrial BSc dissertation. University of Coimbra, Coimbra, Portugal

Plaza, S., Calafell, F., Bertranpetit, J. \& Comas, D. (2001) Mitochondrial genome analysis in Human populations from the western Mediterranean Poster presented in the Euroconference "Inherited Disorders and their Genes in Different European Populations, Exploring Human Genetic Variability." Sant Feliu de Guíxols, Spain, 15-19 November.

Quintana-Murci, L., Semino, O., Bandelt, H.-J., Passarino, G., McElreavery, K. \& Santachiara-Benerecetti, A. S. (1999) Genetic evidence of an early exit of Homo sapiens 
sapiens from Africa through eastern Africa. Nature Genetics 23, 437-147.

Rando, J. C., Cabrera, V. M., Larruga, J. M., Hernández, M., González, A. M., Pinto, F. \& Bandelt, H.-J. (1999) Phylogeographic patterns of mtDNA reflecting the colonization of the Canary islands. Ann Hum Genet 63, 413428.

Rando, J. C., Pinto, F., González, A. M., Hernández, M., Larruga, J. M, Cabrera, V. M. \& Bandelt, H.-J. (1998) Mitochondrial DNA analysis of Northwest African populations reveals genetic exchanges with European, NearEastern, and sub-Saharan populations. Ann Hum Genet 62, 531-550.

Raymond, M. \& Rousset, F. (1995) An exact test for population differentiation. Evolution 49, 12801283.

Reynolds, J., Weir, B. \& Cockerham, C. (1983) Estimation of the coancestry coefficient: basis for short-term genetic distance. Genetics 105, 767-779.

Richards, M. \& Macaulay, V. (2000) Genetic data and the colonization of Europe: genealogies and founders. In: $A r$ chaeogenetics: DNA and the population prehistory of Europe (eds. C. Renfrew \& K. Boyle), pp. 139-151. McDonald Institute for Archaeological Research, Cambridge

Richards, M., Macaulay, V., Bandelt, H. J. \& Sykes, B. C. (1998) Phylogeography of mitochondrial DNA in western Europe. Ann Hum Genet 62, 241-260.

Richards, M., Macaulay, V., Hickey, E., Veja, E., Sykes, B., Guida, V., Rengo, C., Sellitto, D., Cruciani, F., Kivisild, T., Villems, R., Thomas, M., Rychkov, S., Rychkov, O., Rychkov, Y., Golge, M., Dimitrov, D., Hill, E., Bradley, D., Romano, V., Cali, F., Vona, G., Demaine, A., Papiha, S., Triantaphyllidis, C., Stefanescu, G., Hatina, J., Belledi, M., Di Rienzo, A., Novelletto, A., Oppenheim, A., Norby, S., Al-Zaheri, N., Santachiara-Benerecetti, S., Scozzari, R., Torroni, A. \& Bandelt, H.-J. (2000) Tracing European founder lineages in the Near Eastern mtDNA pool. $A m J$ Hum Genet 67, 1251-1276.

Rousselet, F. \& Mangin, P. (1998) Mitochondrial DNA polymorphisms: a study of 50 French Caucasians individuals and application to forensic casework. Int J Legal Med 111(6), 292-298.

Saillard, J., Magalhaes, P. J., Schwartz, M., Rosenberg, T. \& Norby, S. (2000) Mitochondrial DNA variant $11719 \mathrm{G}$ is a marker for the mtDNA haplogroup cluster HV. Hum Biol 72(6), 1065-1068.

Saitou, N. \& Nei, M. (1987) The neighbor-joining method: a new method for reconstructing phylogenetic trees. $\mathrm{Mol}$ Biol Evol 4(4), 406-425.

Salas, A., Comas, D., Laureu, M., Bertranpetit, J. \& Carracedo, A. (1998) mtDNA analysis of the Galician population: a genetic edge of European variation. Eur J Hum Genet 6, $365-375$.
Santos, C. (2001) Haplogrupos del DNAmt en la población de las Azores (Portugal) MSc dissertation. University Autónoma of Barcelona, Barcelona, Spain.

Schneider, S., Roessli, D. \& Excoffier, L. (2000) ARLEQUIN ver 2.000: A software for population genetics data analysis Genetics and Biometry Laboratory, University of Geneva, Switzerland.

Smith, M., Abade, A. \& Cunha, E. (1992) Genetic structure of the Azores: marriage ad inbreeding in Flores. Ann Hum Biol 19(6), 595-601.

SPSS Inc., 1989-1999. SPSS for Windows - Release 9.0.0 Chicago.

Tajima, F. (1983) Evolutionary relationship of DNA sequences in finite populations. Genetics 105, 437-460.

Thomas, H. (1998) The slave trade - the history of the Atlantic slave trade 1440-1870. London: Macmillan Publishers Ltd.

Thomas, M., Weale, M., Jones, A., Richards, M., Smith, A., Redhead, N., Toroni, A., Scozzari, R., Gratrix, F., Tarekegn, A., Wilson, J., Capelli, C., Bradman, N. \& Goldstein, D. (2002) Founding mothers of Jewish communities: geographically separated Jewish groups were independently founded by very few female ancestors. $A m J$ Hum Genet 70, 1411-1420.

Torroni, A. \& Wallace, D. C. (1994) Mithochondrial DNA variation in human populations and implications for detection of mitochondrial DNA mutations of pathological significance. J Bioenerg Biomembr 26, 261-271.

Torroni, A., Huoponen, K., Francalacci, P., Petrozzi, M., Morelli, L., Scozzari, R., Obinu, D., Savontaus, M. L. \& Wallace, D. C. (1996) Classification of European mtDNAs from an analysis of three European populations. Genetics 144, 1835-1850.

Torroni, A., Bandelt, H.-J., d'Urbano, L., Lahermo, P., Moral, P., Sellitto, D., Rengo, C., Forster, P., Savontaus, M. L., Bonne-Tamir, B. \& Scozzari, R. (1998) mtDNA analysis reveals a major late Paleolithic population expansion from southwestern to northeastern Europe. Am J Hum Genet 62, 1137-1152.

Torroni, A., Bandelt, H.-J., Macaulay, V., Richards, M., Cruciani, F., Rengo, C., Martinez-Cabrera, V., Villems, R., Kivisild, T., Metspalu, E., Parik, J., Tolk, H. V., Tambets, K., Forster, P., Karger, B., Francalacci, P., Rudan, P., Janicijevic, B., Rickards, O., Savontaus, M. L., Huoponen, K., Laitinen, V., Koivumaki, S., Sykes, B., Hickey, E., Novelletto, A., Moral, P., Sellitto, D., Coppa, A., Al-Zaheri, N., Santachiara-Benerecetti, A. S., Semino, O. \& Scozzari, R. (2001) A signal, from human mtDNA, of postglacial recolonization in Europe. Am J Hum Genet 69, 844-852.

Torroni, A., Lott, M., Cabell, M., Chen, Y. S., Lavergne, L. \& Wallace, D. C. (1994) mtDNA and the origin of Caucasians. Identification of ancient Caucasian-specific haplogroups, one of which is prone to a recurrent somatic duplication in the D-loop region. Am J Hum Genet 55, 760-776. 
Torroni, A., Schurr, T., Cabell, M., Brown, M. D., Neel, J. V., Larsen, M., Smith, D. G., Vullo, C. M. \& Wallace, D. C. (1993) Asian affinities and continental radiation of the four founding Native Americans mtDNAs. Am J Hum Genet 53, 563590.
Watson, E., Foster, P., Richards, M. \& Bandelt, H.-J. (1997) Mitochondrial footprints of human expansion in Africa. Am J Hum Genet 61, 691-704.

Received: 2 October 2002

Accepted: 13 December 2002 